\title{
Multi-point Sources Continuous Release Inversion Based on Improved Four-Dimensional Variation Method
}

HAN CHAOSHUAI ( $\square$ hanzaoshuai@163.com )

State Key Laboratory of NBC Protection for Civilian https://orcid.org/0000-0002-0764-7654

Xuezheng Zhu

State Key Laboratory of NBC Protection for Civilian

Jin Gu

State Key Laboratory of NBC Protection for Civilian

Qinwen Zuo

State Key Laboratory of NBC Protection for Civilian

\section{Research Article}

Keywords: Convection-Diffusion Equation, Multi-point Sources, Source Term Inversion, Four-Dimensional Variation, Numerical Simulation

Posted Date: October 21st, 2021

DOI: https://doi.org/10.21203/rs.3.rs-989442/v1

License: (c) (i) This work is licensed under a Creative Commons Attribution 4.0 International License. Read Full License 
1 Institute of NBC Defence, Beijing, China

52 State Key Laboratory of NBC Protection for Civilian, Beijing, China

6 The corresponding author: Xuezheng Zhu, email: zxm4x@aliyun.com.

7 Funding: Ministry of Science and Technology of the People's Republic of China

8 (2018YFC0214100)

Abstract: the continuous release of multi-point sources is one of the most common cases in the field of air pollution. In order to solve the problem of multi-point sources continuous release inversion, a source intensity and location estimation method based on improved Four-Dimensional Variation is proposed. Firstly, by constructing the diffusion equation of multi-point sources continuous release and the monitoring concentration matrix, the source term inversion model of multi-point sources continuous release is formed. Secondly, the joint transformation method and Taylor series upwind difference method are used to solve the convection-diffusion equation of multi-point sources continuous release, and the numerical solution format of the forward problem is formed through simulation analysis. Furthermore, based on the numerical solution scheme of the forward problem, a four-dimensional variation inversion algorithm for multi-point sources continuous release is constructed, and the flower pollination algorithm is used to improve the inversion accuracy and computational efficiency. Finally, the applicability, feasibility, advantages and disadvantages of the improved four-dimensional variation algorithm are verified by numerical simulation analysis. It is found that the improved four-dimensional variation algorithm can realize the source term inversion under three conditions: the location is known and the intensity is unknown, the intensity is known and the location is unknown, the intensity and the location are all unknown, which the accuracy and computational efficiency can basically meet the actual needs.

Keywords: Convection-Diffusion Equation; Multi-point Sources; Source Term Inversion; FourDimensional Variation; Numerical Simulation

\section{Introduction}

As an inverse problem of air pollution diffusion prediction, source term inversion (STI) has important practical significance for accurately predicting the temporal and spatial transmission of pollutants, effectively alleviating and curbing pollution sources, which is a key basic technology in the field of air diffusion (Andrew J. Annunzio et al., 2012). Source term information mainly includes source type, source location, source intensity, release time and release mode (continuous and instantaneous), where the complexity and nonlinear characteristics of diffusion process are important reasons for the difficulty of direct inverse derivation and solution of STI (Castelli S.T., 2017). At the same time, there can be no single point source pollution in the actual environment. The expansion from single source inversion to multi-source inversion has become the focus and difficulty of current research. Therefore, this paper carries out theoretical and Simulation Research on multi-point sources continuous 
release inversion, and then carries out multi-point sources instantaneous and mixed release inversion.

For multi-point sources continuous release inversion problem, the key and difficulty lies in the model representation of multiple generalized Dirichlet functions in forward problem solving and inverse problem tracing. In solving the forward problem of convection diffusion equation, Wei T. et al. (2016) transformed the convection-diffusion equation into an integral equation by using Laplace transform, and derived the approximate solution of the typical diffusion equation by orthogonalization and solving Chebyshev polynomials. Based on the relationship between Taylor series expansion and volume average flow, Pan Dartzi (2017) reconstructed the local flow field with high-order piecewise polynomials, and then proposed a spatial high-order finite volume method for solving convection diffusion equations. François et al. (2021) proposed a new super conjugate collocation scheme based on the central finite difference scheme for the forward solution of convection-diffusion equations. Wang Lei et al. (2021) constructed an improved regularized lattice Boltzmann model to solve the convectiondiffusion equation with source term information by Chapman-Enskog analysis of the total distribution function, which was found having higher stability and accuracy than other traditional models. Different from others, Kazakov et al. (2021) used the method of characteristic series and coefficient recursion to obtain the exact solution model of convectiondiffusion equation, and constructed the approximate solution algorithm by boundary element method and dual reciprocity method.

In terms of tracing the source of the inverse problem of convection-diffusion equation, Viktor et al. (2010) proposed a radial basis function meshless method based on finite difference method and Tikhonov, which has the advantage of avoiding singular integral. Then Reza pourgholi et al. (2019) further improved the stability of the method and used it to solve the nonlinear convection-reaction-diffusion equation with unknown source function. Hamba et al. (2012) studied the filtering effect of convection-diffusion equation from two aspects of concentration field and concentration flux, and obtained the value range of filtering width suitable for point source reverse identification. Sun C. L. et al. (2017) proposed a multi-source inversion method based on error functional minimum and homotopy regularization to solve the spatial correlation diffusion coefficient and source coefficient in multiple time fractional diffusion equations. Liu C. S. et al. (2019) proposed a super-position of homogenization functions method (SHFM) for source term identification of nonlinear convection-diffusion equation under unknown boundary conditions, which was applied to one-dimensional diffusion equation. Ruan et al. (2020) proposed a STI algorithm based on Laplace transform and Tikhonov regularization. Through the uniqueness of the forward problem, the convergence of 
the inverse problem and numerical simulation analysis, its feasibility in time fractional diffusion equation was verified. Liu Hailiang (2021) proposed a direct discontinuous Galerkin (DDG) method to characterize the non physical oscillation phenomenon in the convection-diffusion equation, which has strong applicability to improve the stability of the inversion algorithm.

In recent years, with the rapid development of computer technology, the huge computational demand brought by adjoint model has been effectively solved, which provides a key foundation for the popularization and application of Four-Dimensional Variation (4DVAR). Compared with regularization methods and other Assimilation Algorithms, 4DVAR has the advantages of assimilating multiple continuous time windows and stronger universality, which has been applied to various fields such as air pollution, tidal simulation, dust emission, Kuroshio prediction and has attracted more and more attention (Genc D. et al., 2010; Zhang J. C. et al., 2014; Jianbing Jin et al., 2018; Kim Sung min et al., 2019; Yasumasa Miyazawa et al., 2020). In terms of chemical hazard diffusion STI, Kuo et al. (2016) used polynomial expansion method to discretize the differential equation in two dimensions of time and space for the twodimensional time-varying heat source identification problem, and then solved the discretized equations by 4DVAR, and finally obtained the ideal heat source function. Huang S. X. et al. (2018) proposed a pollution source dynamic inversion and grid quantitative traceability algorithm based on CAMx numerical prediction model, which can quickly and quantitatively trace the emission source and contribution rate of air pollution in the next 7 days. Liu Y. et al. (2017, 2019) used 4DVAR Cost Gradient Function and Truncated Total Teast Squares (TTLSVAR) to regularize and correct the error between diffusion prediction operator and observation value, which reduced the error of inversion algorithm and improved the accuracy compared with the basic 4DVAR algorithm. Hassan et al. (2020) proposed a quantitative traceability algorithm combining improved variational iteration and Laplace transform, and applied it to the inverse solution of fractional nonlinear convection-diffusion equation for the first time. Naus et al. (2021) applied 4DVAR to the inversion of Methyl Chloroform (MCF) distribution in the atmosphere, studied the interannual variation of MCF from 1998 to 2018, and then put forward scientific and reasonable strategies for emission reduction regulation.

According to the former study, although the research and application of 4DVAR is relatively mature, there are few related studies in the case of multi-point sources and continuous release. It is of great research value to use 4DVAR to solve the inversion problem of multi-point sources continuous release. In addition, although most 4DVAR algorithms are composed of target functional, gradient model, numerical prediction tangent linear operator, background error covariance matrix and observation error covariance matrix, the construction methods and suitability of each module vary greatly in different fields and situations. How to build a suitable 
110 4DVAR algorithm becomes the key to solve the inversion problem of continuous release of 111 multi-point sources. Therefore, for the problem of continuous release inversion of multi-point 112 sources, a source term inversion algorithm based on improved 4DVAR is proposed in this paper.

113 Firstly, based on the joint transformation method and Taylor series upwind difference method,

114 the analytical solution and numerical solution models of multi-point sources continuous release 115 convection-diffusion equation are constructed respectively. Secondly, based on the research of 116 the forward problem, the improved 4DVAR algorithm is designed from five dimensions: 117 gradient model, numerical prediction tangent linear operator, background error covariance 118 matrix, observation error covariance matrix and intelligent optimization iterative algorithm.

119 Finally, the advantages and disadvantages of the improved 4DVAR algorithm are verified by 120 numerical simulation and field tracer test.

\section{Modeling of Multi-point Sources Continuous Release Inversion Problem}

Usually, the diffusion of continuous release is the most common and practical. In the case of continuous release, the pollution source continuously and evenly releases hazardous gases or aerosols, and the released hazardous substances continue to diffuse along the wind direction. According to the law of mass conservation, combined with the convection diffusion equation and the calculation formula of dry and wet sedimentation effect (Pan Y. P. et al., 2015), without considering the chemical reaction between heterogeneous hazards, the basic equation of the migration mode of continuous release from multi-point sources is as follows:

$$
\left\{\begin{array}{l}
\frac{\partial C}{\partial t}=\nabla(\boldsymbol{D} \nabla C)-\boldsymbol{v} \nabla C-\left(v_{d}+I \cdot l\right) C+\sum_{i=1}^{n} Q_{i} \delta\left(\left|x-x_{i}\right|+\left|y-y_{i}\right|+\left|z-z_{i}\right|\right) \\
C(x, y, z, 0)=\varphi(x, y, z) \\
C(s, k, h, t)=0 \\
(t \geq 0,0 \leq x \leq s, 0 \leq y \leq k, 0 \leq z \leq h)
\end{array}\right.
$$

Where, $C=C(x, y, z, t)$ is the concentration at any point $(x, y, z)$ in the space at time $t ; \boldsymbol{D}=\left(D_{x}\right.$, $\left.D_{y}, D_{z}\right)$ is the atmospheric diffusion coefficient tensor; $\boldsymbol{v}=\left(v_{x}, v_{y}, v_{z}\right)$ is the convective velocity vector; $v_{d}$ is the aerosol dry deposition rate; $I$ is the intensity of rain (snow); $l$ is the removal rate of hazardous substances in the air, which is obtained according to the mass concentration of hazardous substances in rain (snow) particulate phase and atmospheric particulate phase; $n$ is the number of hazard sources; $Q_{i}$ is the source intensity of the $i$ th continuous release point; $\left(x_{i}, y_{i}, z_{i}\right)$ is the position coordinate of the $i$ th continuous release point source; $\delta$ is Dirac function.

STI is the inverse tracing of the multi-point sources convection-diffusion equation in equation (1). However, due to the nonlinear characteristics of multi-point sources diffusion, the number, location coordinates and intensity expressions of hazard sources cannot be obtained by reverse derivation. Therefore, the inverse problem of hazard source number, location 
70

coordinates and intensity identification needs to be formed according to the concentration distribution data of hazards at different times and combined with equation (1). Assume the hazardous substance monitoring concentration matrix of any monitoring point $j\left(x_{j}, y_{j}, z_{j}\right)$ at each observation time is:

$$
c\left(x_{j}, y_{j}, z_{j}, T\right)=\left[c_{1}, c_{2}, \cdots, c_{M}\right], T=\left[t_{1}, t_{2}, \cdots, t_{m}\right]
$$

Where, $T$ is the observation time array. In this way, the inversion problem of multi-point sources continuous release source term can be formed from equations (1) and (2). The parameters to be solved are $\left(n, Q[], X_{0}[], Y_{0}[], Z_{0}[]\right)$. Next, the solution format of the forward problem is given, and then the STI problem will be solved by improved 4DVAR.

\section{Solution of Forward Problem}

\subsection{Analytical solution based on joint transformation method}

Assuming that the hazard is simultaneously released at multiple locations, the concentration of the hazard at any point $(x, y, z)$ in the space at time $t$ is determined by the sum of the diffusion concentration of each hazard source at that location at time $t$. Using Fourier transform and inverse Laplace transform (Karl Barnes, 2017), the analytical expression of multi-point sources continuous release convection-diffusion equation can be obtained, as shown in the following formula:

$$
C(x, y, z, t)=\frac{\sum_{i=1}^{n} \sqrt{\pi} Q_{i}}{2 \sqrt{D_{x} D_{y} D_{z}}}\left\{\begin{array}{c}
\frac{1}{(t)^{3 / 2}} \exp \left[-\frac{1}{4}\left(\frac{\left(x-x_{i}-v_{x} t\right)^{2}}{D_{x} t}+\frac{\left(y-y_{i}-v_{y} t\right)^{2}}{D_{y} t}+\frac{\left(z-z_{i}-v_{z} t\right)^{2}}{D_{z} t}\right)-\left(v_{d}+I \cdot l\right) t\right]+\int_{0}^{t} \frac{\tau}{(t-\tau)^{3 / 2}} \\
\exp \left[-\frac{\left(x-v_{x}(t-\tau)-x_{i}\right)^{2}}{4 D_{x}(t-\tau)}-\frac{\left(y-v_{y}(t-\tau)-y_{i}\right)^{2}}{4 D_{y}(t-\tau)}-\frac{\left(z-v_{z}(t-\tau)-z_{i}\right)^{2}}{4 D_{z}(t-\tau)}-\left(v_{d}+I \cdot l\right)(t-\tau)\right] d \tau
\end{array}\right\}
$$

Where, the definitions of parameters are the same as above.

\subsection{Numerical solution based on Taylor series upwind difference}

In the following, the difference method is used for numerical solution of the multi-point sources continuous release diffusion problem. For convection-diffusion equation, the upwind scheme is the best effect when the boundary conditions and parameters are fixed (He W. P. et al., 2004). Considering that the main influencing factor of chemical hazard diffusion is the convection term, in order to reduce the diffusion prediction error, Taylor series upwind difference is used to difference the equation (1). Assuming that $\Delta x, \Delta y, \Delta z$ are spatial discrete step size and $\Delta t$ is time discrete step size, the difference equation is expressed as follows:

$$
\frac{C_{x, y, z}^{t+1}-C_{x, y, z}^{t}}{\Delta t}
$$

$$
=\left(D_{x}+\frac{v_{x} \cdot \Delta x}{2}\right) \cdot \frac{C_{x-1, y, z}^{t}+C_{x+1, y, z}^{t}-2 C_{x, y, z}^{t}}{\Delta x^{2}}+\left(D_{y}+\frac{v_{y} \cdot \Delta y}{2}\right) \cdot \frac{C_{x, y-1, z}^{t}+C_{x, y+1, z}^{t}-2 C_{x, y, z}^{t}}{\Delta y^{2}}
$$

$$
+\left(D_{z}+\frac{v_{z} \cdot \Delta z}{2}\right) \cdot \frac{C_{x, y, z-1}^{t}+C_{x, y, z+1}^{t}-2 C_{x, y, z}^{t}}{\Delta z^{2}}-v_{x} \cdot \frac{C_{x+1, y, z}^{t}-C_{x-1, y, z}^{t}}{2 \Delta x}-v_{y} \cdot \frac{C_{x, y+1, z}^{t}-C_{x, y-1, z}^{t}}{2 \Delta y}-v_{z}
$$

$$
\cdot \frac{C_{x, y, z+1}^{t}-C_{x, y, z-1}^{t}}{2 \Delta z}-\left(v_{d}+I \cdot l\right) \cdot C_{x, y, z}^{t}+f(x, y, z)
$$


Where, $f(x, y, z)=\sum_{i=1}^{n} Q_{i} \delta\left(\left|x-x_{i}\right|+\left|y-y_{i}\right|+\left|z-z_{i}\right|\right)$. Get the difference equation about $C_{x, y, z}^{t+1}$ :

$$
C_{x, y, z}^{t+1}=\Delta t \cdot\left\{\begin{array}{c}
\left(D_{x}+\frac{v_{x} \cdot \Delta x}{2}\right) \cdot \frac{C_{x-1, y, z}^{t}+C_{x+1, y, z}^{t}-2 C_{x, y, z}^{t}}{\Delta x^{2}}+\left(D_{y}+\frac{v_{y} \cdot \Delta y}{2}\right) \\
\cdot \frac{C_{x, y-1, z}^{t}+C_{x, y+1, z}^{t}-2 C_{x, y, z}^{t}}{\Delta y^{2}}+\left(D_{z}+\frac{v_{z} \cdot \Delta z}{2}\right) \cdot \\
\frac{C_{x, y, z-1}^{t}+C_{x, y, z+1}^{t}-2 C_{x, y, z}^{t}}{\Delta z^{2}}-v_{x} \cdot \frac{C_{x+1, y, z}^{t}-C_{x-1, y, z}^{t}}{2 \Delta x}-v_{y} \cdot \\
\frac{C_{x, y+1, z}^{t}-C_{x, y-1, z}^{t}}{2 \Delta y}-v_{z} \cdot \frac{C_{x, y, z+1}^{t}-C_{x, y, z-1}^{t}}{2 \Delta z}-\left(v_{d}+I \cdot l\right) \cdot C_{x, y, z}^{t}+f(x, y, z)
\end{array}\right\}+C_{x, y, z}^{t}
$$

Let $p_{x}=\frac{D_{x} \Delta t}{\Delta x^{2}}, p_{y}=\frac{D_{y} \Delta t}{\Delta y^{2}}, p_{z}=\frac{D_{z} \Delta t}{\Delta z^{2}}, q_{x}=\frac{v_{x} \Delta t}{2 \Delta x}, q_{y}=\frac{v_{y} \Delta t}{2 \Delta y}, q_{z}=\frac{v_{z} \Delta t}{2 \Delta z}$. Then the difference equation of $C_{x, y, z}^{t+1}$ is simplified to:

$$
\begin{gathered}
C_{x, y, z}^{t+1}=\left(p_{x}+2 q_{x}\right) C_{x-1, y, z}^{t}+\left(p_{y}+2 q_{y}\right) C_{x, y-1, z}^{t}+\left(p_{z}+2 q_{z}\right) C_{x, y, z-1}^{t} \\
+\left[-2\left(p_{x}+q_{x}+p_{y}+q_{y}+p_{z}+q_{z}\right)-\left(v_{d}+I \cdot l\right) \Delta t+1\right] C_{x, y, z}^{t}+p_{x} C_{x+1, y, z}^{t}+p_{y} C_{x, y+1, z}^{t}+p_{z} C_{x, y, z+1}^{t}+ \\
\Delta t \cdot f(x, y, z)
\end{gathered}
$$

The initial boundary value condition can be discretized as follows:

$$
\left\{\begin{array}{l}
C_{x, y, z}^{0}=f(x, y, z) \\
C_{s, k, h}^{t}=0
\end{array}\right.
$$

In combination with equations (5) and (6), the concentration value iterative matrix $\boldsymbol{C}^{t+1}$ of each grid point at time $t+1$ can be obtained as follows:

$$
\boldsymbol{C}^{t+1}=\boldsymbol{A} \boldsymbol{C}^{t}+\Delta t \cdot \boldsymbol{f}
$$

Where, $\boldsymbol{C}^{t}=\left(C_{x_{1}, y_{1}, z_{1}}^{t}, C_{x_{2}, y_{2}, z_{2}}^{t}, C_{x_{3}, y_{3}, z_{3}}^{t}, \cdots, C_{x_{M}, y_{M}, z_{M}}^{t}\right)^{T}$, which is the concentration value matrix of each grid point at time $t$; Each point is numbered in the positive direction of $x$, $y$ and $z$ axes, and $M$ is the total number of grids; $\boldsymbol{f}=\left(f\left(x_{1}, y_{1}, z_{1}\right), f\left(x_{2}, y_{2}, z_{2}\right)\right.$, $\left.f\left(x_{3}, y_{3}, z_{3}\right), \cdots, f\left(x_{M}, y_{M}, z_{M}\right)\right)^{T} ; \boldsymbol{A}=\left[a_{i j}\right]_{M \times M}, i, j=1,2, \cdots, M$. The value rule of $a_{i j}$ is as follows:

$$
a_{i j}=\left\{\begin{array}{cc}
0, & j<i-3 \\
p_{x}+2 q_{x}, & j=i-3, \\
p_{y}+2 q_{y}, & j=i-2 \\
p_{z}+2 q_{z} & j=i-1 \\
-2\left(p_{x}+q_{x}+p_{y}+q_{y}+p_{z}+q_{z}\right)-\left(v_{d}+I \cdot l\right) \Delta t+1, & j=i \\
p_{x}, & j=i+1 \\
p_{y}, & j=i+2 \\
p_{z,} & j=i+3 \\
0, & j>i+3
\end{array}\right.
$$

The truncation error of equation (7) is $O(\Delta t+\Delta x+\Delta y+\Delta z)$. According to the stability criterion of the difference scheme, the stability and convergence conditions of the difference expression are as follows:

$$
\left\{\begin{array}{l}
p_{x}+q_{x} \leq \frac{1}{2} \\
p_{y}+q_{y} \leq \frac{1}{2} \\
p_{z}+q_{z} \leq \frac{1}{2}
\end{array}\right.
$$


Equation (8) is the normalization constraint on meshing.

\subsection{Numerical simulation analysis}

Combined with the stability and convergence constraints of equation (8), taking onedimensional numerical simulation as an example, the analytical solution and numerical solution are compared and analyzed. The parameter settings are as follows: spatial step size $d x=1$, spatial steps $N=14$, time step size $d t=1$, time steps $M=10, D x=0.35, v x=0.25$, the number of hazard sources is 2 , the coordinates are [2,5], and the intensity of hazard sources is $Q 1=1$ and $Q 2=2$ respectively. The calculation results are shown in Figure 1 and Figure 2.

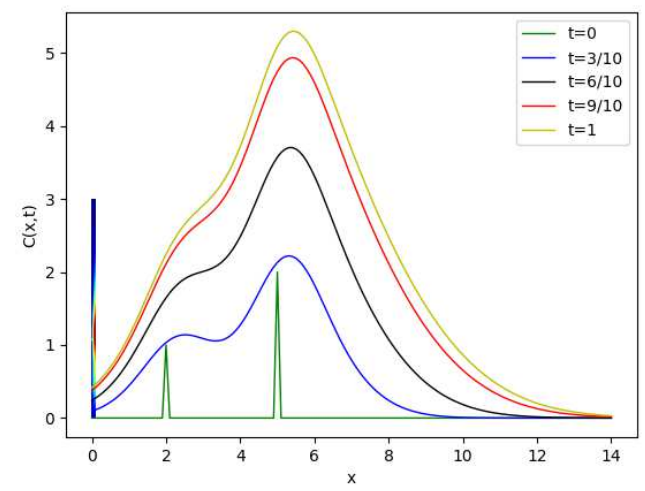

Fig.1. Analytical simulation of one dimensional convection-diffusion equation

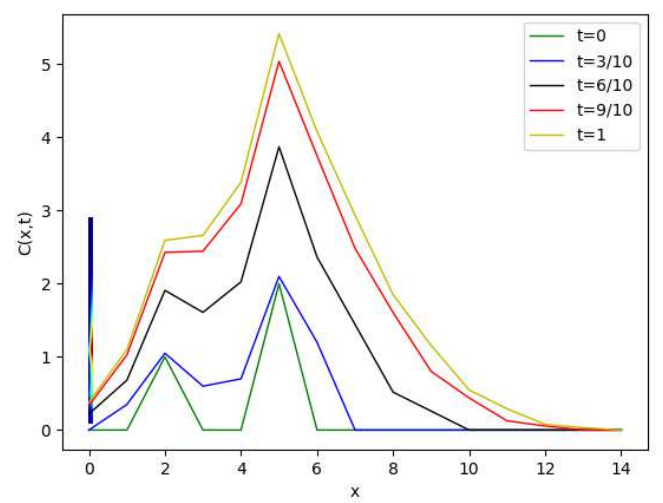

It can be seen from Figure 1 and Figure 2 that except for obvious differences at individual points, the numerical solution and analytical solution are in good agreement as a whole. The main reason for the difference is the truncation error $O(\Delta t+\Delta x)$ of the difference equation. Next, considering the inverse problem on the basis of solving the forward problem, an improved 4DVAR algorithm for multi-point STI is constructed to estimate the source intensity and position.

The mathematical expression of variational method refers to the functional extreme value problem with constraints. Based on the theory of maximum likelihood estimation, it interpolates 
the observed data to the preset mode lattice, and constructs a target functional by measuring the distance between the model field and the observation field (Fairbairn D. et al., 2014). Compared with other assimilation methods, 4DVAR realizes the assimilation of observed data in the whole assimilation time window, with higher prediction accuracy and wider application range. Based on the traditional 4DVAR, this paper constructs the gradient model, tangent linear operator of numerical prediction, background error covariance matrix and observation error covariance matrix suitable for multi-point sources continuous release, solves the gradient model by using the Improved Flower Pollination Algorithm (IFPA), and finally obtains the multi-point sources continuous release inversion algorithm.

\subsection{Gradient model of multi-point STI}

According to the multi-point sources continuous release convection-diffusion equation (equation (1)) and the 4DVAR assimilation principle, the multi-point source inversion target functional model under continuous release is constructed as follows:

$J_{4 D}(\boldsymbol{C})=J_{4 D}^{b}\left(c_{0}\right)+J_{4 D}^{r}(\boldsymbol{C})=$

$$
\frac{1}{2}\left(\sum_{i=1}^{n} \boldsymbol{c}_{i, 0}-\boldsymbol{c}_{b}\right)^{T} \boldsymbol{B}^{-1}\left(\sum_{i=1}^{n} \boldsymbol{c}_{i, 0}-\boldsymbol{c}_{b}\right)+\frac{1}{2} \sum_{t \in T}\left(\sum_{i=1}^{n} H_{t} \cdot \boldsymbol{c}_{i, t}-\boldsymbol{y}_{t}\right)^{T} \boldsymbol{R}^{-1}\left(\sum_{i=1}^{n} H_{t} \cdot \boldsymbol{c}_{i, t}-\boldsymbol{y}_{t}\right)
$$

Where, $\boldsymbol{c}_{0}$ is the initial state vector of hazard sources; $\boldsymbol{c}_{i, 0}$ is the concentration state vector of hazardous substance at the initial time of the $i$ th hazard source; $\mathbf{c}_{b}$ is the background field vector; $H_{t}$ is the observation operator matrix at time $t ; \boldsymbol{y}_{t}$ is the observation vector of hazardous substance concentration at time $t ; \boldsymbol{c}_{i, t}$ is the state vector of diffusion concentration at time $t$ of the $i$ th hazard source; $\boldsymbol{B}$ is the background error covariance matrix; $\boldsymbol{R}$ is the observation error covariance matrix; $T$ is the assimilation time window; Other parameters are the same as above.

For equation (9), it is composed of background and observation, and the process of minimizing is also the superposition of these two parts, namely:

$$
\nabla J_{4 D}\left(c_{0}\right)=\nabla J_{4 D}^{b}\left(c_{0}\right)+\nabla J_{4 D}^{r}\left(c_{0}\right)
$$

Calculate the partial derivative of $J_{4 D}^{b}\left(c_{0}\right)$ in equation (9) directly to obtain its gradient model:

$$
\nabla J_{4 D}^{b}\left(c_{0}\right)=\boldsymbol{B}^{-1}\left(\sum_{i=1}^{n} \boldsymbol{c}_{i, 0}-\boldsymbol{c}_{b}\right)
$$

For the multi-point source continuous release diffusion model, $J_{4 D}^{r}(\boldsymbol{C})$ involves many parameters and vectors, so it is difficult to obtain the partial derivative of $\boldsymbol{c}_{0}$ by direct derivation. Assuming that $J_{4 D}^{r}(\boldsymbol{C})$ is bounded differentiable in Hilbert space, according to the first-order variational properties, we can derived:

$$
\delta J_{4 D}^{r}(\boldsymbol{C})=\left.\frac{d}{d \delta} J_{4 D}^{r}\left(\boldsymbol{c}_{0}+\delta \boldsymbol{c}_{0}\right)\right|_{\delta=0}=\left\langle\nabla J_{4 D}^{r}\left(c_{0}\right), \delta \boldsymbol{c}_{0}\right\rangle
$$

Where, $\delta \boldsymbol{c}_{0}$ is the perturbation of $\boldsymbol{c}_{0}$. Similarly, $\delta J_{4 D}^{r}(\boldsymbol{C})$ is represented by $\nabla J_{4 D}^{r}\left(\boldsymbol{c}_{t}\right)$ 
and $\delta \boldsymbol{c}_{t}$, which is shown as follows:

$$
\delta J_{4 D}^{r}(\boldsymbol{C})=\left\langle\nabla J_{4 D}^{r}\left(\boldsymbol{c}_{t}\right), \delta \boldsymbol{c}_{t}\right\rangle=\left\langle\sum_{t \in T} H_{t}^{T} \boldsymbol{R}^{-1}\left(\sum_{i=1}^{n} H_{t} \cdot \boldsymbol{c}_{i, t}-\boldsymbol{y}_{t}\right), \delta \boldsymbol{c}_{t}\right\rangle
$$

Where, $\boldsymbol{c}_{t}$ is the diffusion concentration state vector of each hazard source at time $t ; \delta \boldsymbol{c}_{t}$ is the perturbation of $\boldsymbol{c}_{t}$; Other parameters are the same as above. Next, just build the relationship between $\delta \boldsymbol{c}_{t}$ and $\delta \boldsymbol{c}_{0}$ to get the $\nabla J_{4 D}^{r}\left(c_{0}\right)$ expression. Assuming that the adjoint model of numerical prediction from time $t$ to time $t+1$ is $\boldsymbol{M}_{t+1}=\left(M_{1, t+1}, M_{2, t+1}, \cdots, M_{m, t+1}\right)$, $m$ is the number of observation points, and $a$ is the set of meteorological parameters and background field parameters in the model, the relationship between $\boldsymbol{c}_{t+1}$ and $\boldsymbol{c}_{t}$ can be obtained as follows:

$$
\boldsymbol{c}_{t+1}=\boldsymbol{M}_{t+1}\left(\boldsymbol{c}_{t}, \boldsymbol{a}\right)
$$

Assuming that $c_{t}^{*}=\boldsymbol{c}_{t}-\delta \boldsymbol{c}_{t}$, which is the state vector without disturbance, then the equation (14) can be converted to:

$$
\left\{\begin{array}{l}
\boldsymbol{c}_{t+1}=\boldsymbol{M}_{t+1}\left(c_{t}^{*}+\delta \boldsymbol{c}_{t}, \boldsymbol{a}\right) \approx \boldsymbol{M}_{t+1}\left(c_{t}^{*}, \boldsymbol{a}\right)+\boldsymbol{D}_{t+1} \cdot \delta \boldsymbol{c}_{t}=c_{t+1}^{*}+\delta \boldsymbol{c}_{t+1} \\
\boldsymbol{D}_{t+1}=\left[D_{1, t+1}, D_{2, t+1}, \cdots, D_{(x, y, z), t+1}, \cdots, D_{m, t+1}\right]^{T}
\end{array}\right.
$$

Where $\boldsymbol{D}_{t+1}$ is the tangent linear operator of $\boldsymbol{M}_{t+1}\left(\boldsymbol{c}_{t}, \boldsymbol{a}\right)$. The relationship between $\delta c_{t+1}$ and $\delta c_{0}$ can be obtained from equation (15), which is shown as follows:

$$
\delta \boldsymbol{c}_{t+1}=\boldsymbol{D}_{t+1} \cdot \delta \boldsymbol{c}_{t}=\boldsymbol{D}_{t+1} \boldsymbol{D}_{t} \cdots \boldsymbol{D}_{1} \cdot \delta \boldsymbol{c}_{0}
$$

Substituting equation (16) into equation (13) and using the conjugate transpose theory, we can derived:

$$
\begin{aligned}
\delta J_{4 D}^{r}(\boldsymbol{C}) & =\left\langle\sum_{t \in T} H_{t}^{T} \boldsymbol{R}^{-1}\left(\sum_{i=1}^{n} H_{t} \cdot \boldsymbol{c}_{i, t}-\boldsymbol{y}_{t}\right), \boldsymbol{D}_{t+1} \boldsymbol{D}_{t} \cdots \boldsymbol{D}_{1} \cdot \delta \boldsymbol{c}_{0}\right\rangle \\
& =\left\langle\sum_{t \in T}\left(\boldsymbol{D}_{t} \boldsymbol{D}_{t-1} \cdots \boldsymbol{D}_{1}\right)^{T} H_{t}^{T} \boldsymbol{R}^{-1}\left(\sum_{i=1}^{n} H_{t} \cdot \boldsymbol{c}_{i, t}-\boldsymbol{y}_{t}\right), \delta \boldsymbol{c}_{0}\right\rangle
\end{aligned}
$$

Combining equations (12) and (17), the partial derivative $\nabla J_{4 D}^{r}\left(c_{0}\right)$ of $J_{4 D}^{r}(\boldsymbol{C})$ to $\boldsymbol{c}_{0}$ can be obtained:

$$
\nabla J_{4 D}^{r}\left(c_{0}\right)=\sum_{t \in T}\left(\boldsymbol{D}_{t} \boldsymbol{D}_{t-1} \cdots \boldsymbol{D}_{1}\right)^{T} H_{t}^{T} \boldsymbol{R}^{-1}\left(\sum_{i=1}^{n} H_{t} \cdot \boldsymbol{c}_{i, t}-\boldsymbol{y}_{t}\right)
$$

Combining equations (11) and (18), the partial derivative $\nabla J_{4 D}\left(c_{0}\right)$ of $J_{4 D}(\boldsymbol{C})$ to $\boldsymbol{c}_{0}$ can be obtained:

$$
\nabla J_{4 D}\left(c_{0}\right)=\boldsymbol{B}^{-1}\left(\sum_{i=1}^{n} \boldsymbol{c}_{i, 0}-\boldsymbol{c}_{b}\right)+\sum_{t \in T}\left(\boldsymbol{D}_{t} \boldsymbol{D}_{t-1} \cdots \boldsymbol{D}_{1}\right)^{T} H_{t}^{T} \boldsymbol{R}^{-1}\left(\sum_{i=1}^{n} H_{t} \cdot \boldsymbol{c}_{i, t}-\boldsymbol{y}_{t}\right)
$$

The above formula is the gradient model of multi-point STI.

\subsection{Tangent linear operator of numerical prediction $\boldsymbol{D}_{t+1}$}

The basis of finding tangent linear operator is to determine the numerical prognostic model of diffusion. Considering that the main factor affecting the diffusion of hazardous substances is the convection term, in order to reduce the diffusion prediction error, the numerical solution of convection-diffusion equation based on Taylor series upwind difference is used as the numerical prediction operator at the observation point $(x, y, z)$ on time $t+1$, as shown in equation (7). According to the numerical prediction operator of each observation point at time $t+1$, the 
numerical prognostic model $\boldsymbol{M}_{t+1}$ of the whole state vector at time $t+1$ can be obtained, where $\boldsymbol{M}_{t+1}=\left(M_{1, t+1}, M_{2, t+1}, \cdots, M_{m, t+1}\right)$.

Assuming that the predicted concentration of hazardous substances at each observation point at time $t$ is $\boldsymbol{c}_{t}=\left(c_{1, t}, c_{2, t}, \cdots, c_{m, t}\right)$, according to the definition of tangent linear operator, the numerical prediction tangent linear operator $\boldsymbol{D}_{t+1}$ at time $t+1$ is obtained:

$$
\boldsymbol{D}_{t+1}=\left[\begin{array}{cccc}
\frac{\partial M_{1, t+1}}{\partial c_{1, t}} & \frac{\partial M_{1, t+1}}{\partial c_{2, t}} & \cdots & \frac{\partial M_{1, t+1}}{\partial c_{m, t}} \\
\frac{\partial M_{2, t+1}}{\partial c_{1, t}} & \frac{\partial M_{2, t+1}}{\partial c_{2, t}} & \cdots & \frac{\partial M_{2, t+1}}{\partial c_{m, t}} \\
\vdots & \vdots & \ddots & \vdots \\
\frac{\partial M_{m, t+1}}{\partial c_{1, t}} & \frac{\partial M_{m, t+1}}{\partial c_{2, t}} & \cdots & \frac{\partial M_{m, t+1}}{\partial c_{m, t}}
\end{array}\right]
$$

$$
\text { Where } \frac{\partial M_{(x, y, z), t+1}}{\partial c_{t}}=\left(\begin{array}{c}
\cdots, p_{x}+2 q_{x}, p_{y}+2 q_{y}, p_{z}+2 q_{z}, \\
1-2\left(p_{x}+q_{x}+p_{y}+q_{y}+p_{z}+q_{z}\right)-\left(v_{d}+I \cdot l\right) \Delta t, \\
p_{x}, p_{y}, p_{z}, \cdots
\end{array}\right) \text {. }
$$

\subsection{Background error covariance matrix $\boldsymbol{B}$}

The background error covariance matrix is used to characterize the error covariance relationship between the background field and the true value. Assuming that the background field error of the chemical hazard concentration at each point in the diffusion space is unbiased, uncorrelated and isotropic, and the background error and observation error are independent of each other, the mathematical expression of the background error variance of the background field on the $i$ th grid point is:

$$
\sigma_{b i}^{2}=\overline{\left(c_{b l}-c_{l}^{t}\right)\left(c_{b l}-c_{l}^{t}\right)}
$$

Where, $c_{i}^{t}$ is the true concentration value of the $i$ th grid point, and $c_{b i}$ is the background field concentration value of the $i$ th grid point; ${ }^{-}$is the average value (Varella H. et al., 2011). The background error covariance matrix $\boldsymbol{B}$ of the background field between $m$ observation points is:

$$
\boldsymbol{B}=\left[\begin{array}{cccc}
\overline{\left(c_{b 1}-c_{1}^{t}\right)\left(c_{b 1}-c_{1}^{t}\right)} & \overline{\left(c_{b 1}-c_{1}^{t}\right)\left(c_{b 2}-c_{2}^{t}\right)} & \cdots & \overline{\left(c_{b 1}-c_{1}^{t}\right)\left(c_{b m}-c_{m}^{t}\right)} \\
\frac{\left.c_{b 2}-c_{2}^{t}\right)\left(c_{b 1}-c_{1}^{t}\right)}{\left(c_{b 2}-c_{2}^{t}\right)\left(c_{b 2}-c_{2}^{t}\right)} & \cdots & \frac{\vdots}{\left(c_{b 2}-c_{2}^{t}\right)\left(c_{b m}-c_{m}^{t}\right)} \\
\frac{\vdots}{\left(c_{b m}-c_{m}^{t}\right)\left(c_{b 1}-c_{1}^{t}\right)} & \frac{\ddots}{\left(c_{b m}-c_{m}^{t}\right)\left(c_{b 2}-c_{2}^{t}\right)} & \cdots & \frac{\vdots}{\left(c_{b m}-c_{m}^{t}\right)\left(c_{b m}-c_{m}^{t}\right)}
\end{array}\right]_{m \times m}
$$

However, the background error covariance matrix ( $\boldsymbol{B}$ matrix) is a very challenging problem in both the field of weather prediction and the field of pollutant diffusion, while the core lies in the difficulty of obtaining the true concentration value of each grid point in the real environment, large dimension of state variables by meshing, and lack of sufficient data samples. Therefore, it is difficult to accurately describe $\boldsymbol{B}$ matrix by equation (22). Generally, $\boldsymbol{B}$ matrix is constructed by physical inference and rough statistics, where the typical construction methods include innovation vector (IV) analysis method, NMC method, potential vorticity characterization method, etc (Rutherford I, 1972; Liu YA et al., 2015; Cullen, 2003). In recent years, with the 
313 development of computer technology, spherical wavelet analysis, set estimation method,

314 covariant Lyapunov vector (CLV) and other methods have emerged (Chabot et al., 2017; Valler

315 Veronika et al., 2019; Quinn C. et al., 2020). Compared with other methods, NMC has attracted 316 more and more attention and application because of its better simplicity of operation, 317 universality of scene and stability of results. Therefore, this paper selects the classical NMC as 318 the basic method to construct $\boldsymbol{B}$ matrix by adjusting the forecast period and increasing the 319 background error correlation coefficient, which is suitable for multi-point sources continuous 320 release inversion. by Parrish and Derber in 1992. Compared with other methods, this method replaces the background error with the integral difference of prediction values at the same time and different prediction aging, which can effectively avoid the shortage of truth value and solve the calculation difficulty caused by too large dimension of state variables (Parrish D. F. et al., 1992). Assuming that $\boldsymbol{c}_{t}^{T}$ is the predicted concentration state vector of observation points with time $t$ and analytical aging $T, \boldsymbol{c}_{t}^{T}=\left(c_{1 t}^{T}, c_{2 t}^{T}, \cdots, c_{m t}^{T}\right)$, Parrish and Derber convert the calculation of $\boldsymbol{B}$ matrix into:

$$
\boldsymbol{B}=\frac{1}{2}\left[\overline{\left(c_{l t}^{48}-c_{l t}^{24}\right)\left(c_{J t}^{48}-c_{j t}^{24}\right)}\right]_{m \times m}
$$

Where, $c_{i}^{48}$ and $c_{i}^{24}$ are the predicted concentration value of $i$ th observation point at time $t$ and analytical aging of $48 h$ and $24 h$ respectively; $1 \leq i \leq m, 1 \leq j \leq m$. Take $t=48 h$ as an example, then

$$
\left\{\begin{array}{l}
\boldsymbol{c}_{48}^{48}=M_{48 \leftarrow 0} \cdot \boldsymbol{y}_{0},(t=0) \\
\boldsymbol{c}_{48}^{24}=M_{48 \leftarrow 24} \cdot \boldsymbol{y}_{24},(t=24 h)
\end{array}\right.
$$

Where, $M_{t 2 \leftarrow t 1}$ is the prognostic model of chemical hazard diffusion from time $t_{1}$ to $t_{2}$; $\boldsymbol{y}_{0}$ and $\boldsymbol{y}_{24}$ are the observed concentration state vectors of the observation points at $t=0$ and $t=24 h$ respectively.

\subsubsection{Correction strategy}

\section{(1) Adjust forecast period}

In addition to extreme weather such as heavy rain and heavy snowfall, in case of major chemical explosion or leakage, the hazardous substances will quickly spread downwind in a

342 few minutes to dozens of minutes and cause large-scale pollution, so it is inappropriate to use $34348 h$ and $24 h$ as analytical aging and forecast time. Therefore, selecting the appropriate forecast 344 period (analytical aging and forecast time) becomes the key to construct the $\boldsymbol{B}$ matrix. If the 345 forecast time is too long, it will affect the rescue and disposal. If it is too short, it is difficult to 
obtain a relatively stable analytical aging. If the analytical aging is too large or too low, it will lead to a large difference between the two analysis field errors and the real background errors.

The main factors affecting the prediction period include: the action duration of hazardous substances, the timeliness requirements of emergency rescue or hazard disposal for diffusion prediction, the general disposal mode of hazardous substances, the data acquisition mode and the use characteristics of monitoring equipment. Comprehensively analyze the influencing factors, adjust the forecast time in equations (23) and (24) to 30min, and the analytical aging to $10 \mathrm{~min}$ and 20min. Then the predicted concentration state vector when the forecast time $t$ is $30 \mathrm{~min}$ and the analytical aging are $10 \mathrm{~min}$ and $20 \mathrm{~min}$ respectively is:

$$
\left\{\begin{array}{l}
\boldsymbol{c}_{30}^{20}=\boldsymbol{M}_{30 \leftarrow 10} \cdot \boldsymbol{y}_{10},(t=10 \mathrm{~min}) \\
\boldsymbol{c}_{30}^{10}=\boldsymbol{M}_{30 \leftarrow 20} \cdot \boldsymbol{y}_{20},(t=20 \mathrm{~min})
\end{array}\right.
$$

Where the parameters definition are the same as above.

(2) Correction based on background error correlation coefficient

In order to ensure the positive definiteness and smoothness of the $\boldsymbol{B}$ matrix, the Gaussian formula close to the actual situation of chemical hazard diffusion is used to construct the background error correlation coefficient, and the background error covariance is formed by multiplying the background error and the correlation coefficient. Assuming any two lattice points $x_{1}$ and $x_{2}$ in the space, the background error correlation coefficient between two points $b\left(x_{1}, x_{2}\right)$ can be expressed as a function of its distance:

$$
b\left(x_{1}, x_{2}\right)=\operatorname{dist}\left(x_{1}-x_{2}\right) e^{-\frac{\operatorname{dist}\left(x_{1}-x_{2}\right)^{2}}{2}}
$$

Where $\operatorname{dist}\left(x_{1}-x_{2}\right)$ is the distance between $x_{1}$ and $x_{2}$ ( Ma Jianwen et al., 2013). Thus, the expression of $\boldsymbol{B}$ matrix can be obtained:

$$
\boldsymbol{B}=\frac{1}{2}\left[b(i, j) \cdot \overline{\left(c_{l 30}^{20}-c_{l 30}^{10}\right)\left(c_{\jmath 30}^{20}-c_{\jmath 30}^{10}\right)}\right]_{m \times m}
$$

Where the parameters definition are the same as above.

\subsection{Observation error covariance matrix $\boldsymbol{R}$}

In 4DVAR, the observation error covariance matrix is used to characterize the error covariance relationship between the analysis field and the true value (Liu Y. A. et al., 2019). The mathematical expression of observation error variance for analysis field on $i$ th grid point $\sigma_{r i}^{2}$ is:

$$
\sigma_{r i}^{2}=\overline{\left(y_{l}-c_{l}^{t}\right)\left(y_{l}-c_{l}^{t}\right)}
$$

Where, $c_{i}^{t}$ is the concentration true value of $i$ th grid point; $y_{i}$ is the concentration observation value of $i$ th grid point. Then the observation error covariance matrix ( $R$ matrix) of analysis field between $m$ observation points can be expressed as follows: 


$$
\boldsymbol{R}=\left[\begin{array}{cccc}
\overline{\left(y_{1}-c_{1}^{t}\right)\left(y_{1}-c_{1}^{t}\right)} & \overline{\left(y_{1}-c_{1}^{t}\right)\left(y_{2}-c_{2}^{t}\right)} & \cdots & \overline{\left(y_{1}-c_{1}^{t}\right)\left(y_{m}-c_{m}^{t}\right)} \\
\overline{\left(y_{2}-c_{2}^{t}\right)\left(y_{1}-c_{1}^{t}\right)} & \frac{\left(y_{2}-c_{2}^{t}\right)\left(y_{2}-c_{2}^{t}\right)}{\vdots} & \cdots & \frac{\vdots}{\left(y_{2}-c_{2}^{t}\right)\left(y_{m}-c_{m}^{t}\right)} \\
\overline{\left(y_{m}-c_{m}^{t}\right)\left(y_{1}-c_{1}^{t}\right)} & \overline{\left(y_{m}-c_{m}^{t}\right)\left(y_{2}-c_{2}^{t}\right)} & \cdots & \frac{\vdots}{\left(y_{m}-c_{m}^{t}\right)\left(y_{m}-c_{m}^{t}\right)}
\end{array}\right]_{m \times m}
$$

It can be seen that $\boldsymbol{R}$ matrix contains statistical information about observation errors. For chemical hazard alarm and monitoring equipment, the observation errors of each observation point are distributed independently of each other. Assuming that the observation error is unbiased and the influence of the observation operator and representative error on the observation results is not considered, the $\boldsymbol{R}$ matrix can be simplified into a diagonal matrix about the instrument error variance, as shown in equation (30).

$$
\boldsymbol{R}=\left[\begin{array}{cccc}
\sigma_{r 1}^{2} & & & \\
& \sigma_{r 2}^{2} & & \\
& & \ddots & \\
& & & \sigma_{r m}^{2}
\end{array}\right]_{m \times m}
$$

\subsection{Intelligent solution of gradient model based on IFPA}

Aiming at the shortcomings of complex calculation for inverse matrix and easy to fall into local convergence or non-convergence of Quasi Newton Algorithm (QNA) in the traditional 4DVAR, the Improved Flower Pollination Algorithm (IFPA) is used as the optimization algorithm for the iterative solution of gradient model. IFPA is an efficient intelligent optimization algorithm proposed by authors (Zhu X. Z., et al., 2021), where the Good-point Set population, Deb feasibility comparison method and $\varepsilon$ constraint method is integrated into Flower Pollination Algorithm (FPA) (Yang X. S., 2012), which can comprehensively improves the global optimization ability of FPA and the flexibility to deal with different constraint problems. Compared with Particle Swarm Optimization Algorithm (PSO), Artificial Bee Colony Algorithm (ABCA), Coevolutionary Differential Evolution Algorithm (CDE) and other methods, IFPA is not limited by the unconnected feasible region, does not required to repeatedly derive objective function gradient in process of solving, and significantly improves the calculation rate. The basic steps of gradient model solution using IFPA are as follows:

Step 1: Define flower individuals (source intensity, quantity or location), set flower population size $N$, pollination mode conversion probability $P$, maximum iteration times $T$ and other parameters to form the initial population.

Step 2: Let $t=1, k=1$, traverse each population, calculate the $\nabla J_{4 D}\left(c_{0}\right)$ value of each flower in each population, analyze the stability and convergence of each flower, eliminate unstable flowers and generate a new flower population.

Step 3: For the new flower population, calculate the $\nabla J_{4 D}\left(c_{0}\right)$ value of each flower, search for the best flower $X_{b}^{t}$. 


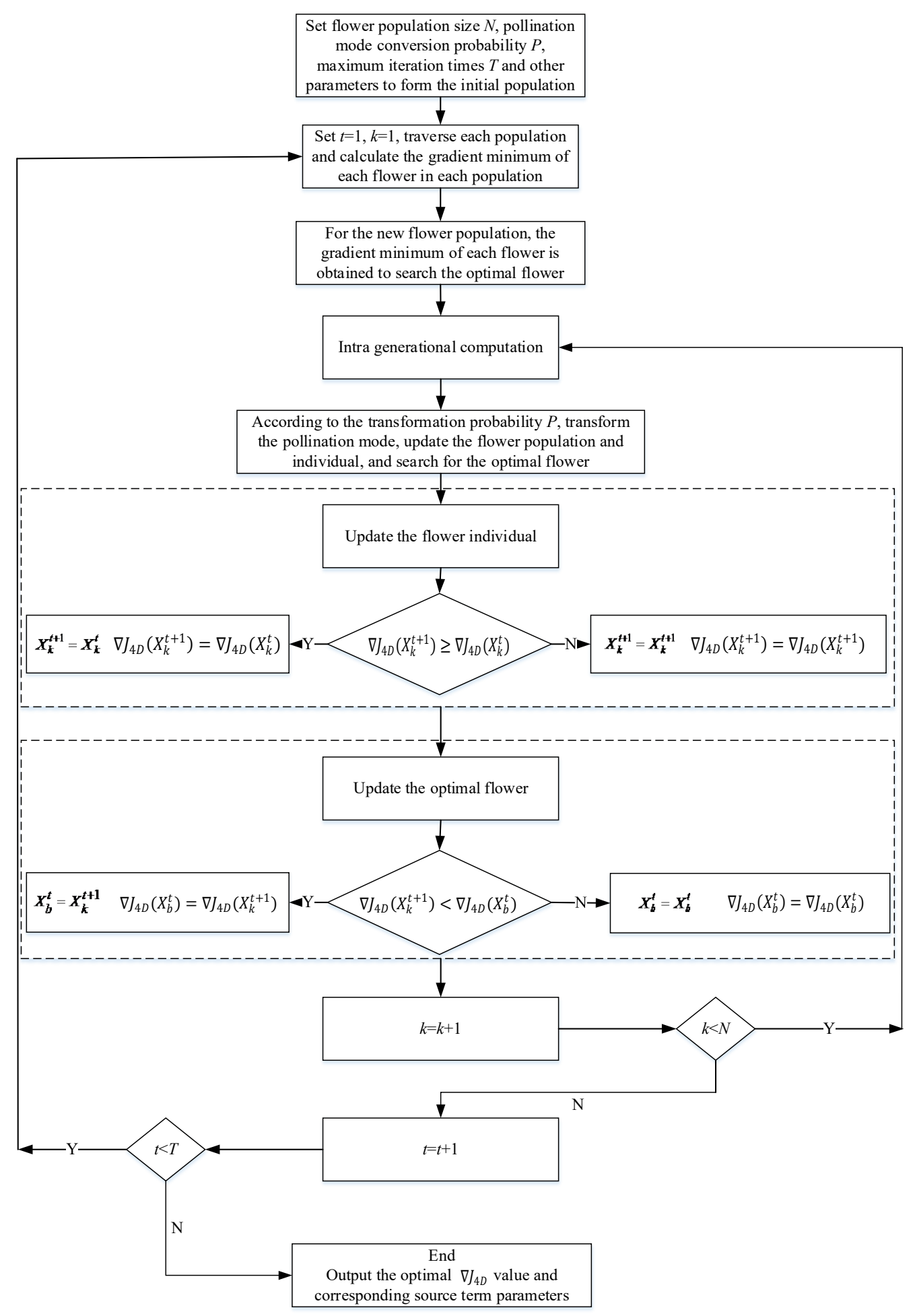

Fig.3 Basic process of gradient model optimization based on IFPA

$410 \quad$ Step 4: Perform intra generational computation.

411 Step 5: According to the transformation probability $P$, transform the pollination mode, 412 update the flower population and individual, and search for the optimal flower.

413 Step 6: Update the flower individual. If $\nabla J_{4 D}\left(X_{k}^{t+1}\right) \geq \nabla J_{4 D}\left(X_{k}^{t}\right)$, then $X_{k}^{t+1}=X_{k}^{t}$, $414 \nabla J_{4 D}\left(X_{k}^{t+1}\right)=\nabla J_{4 D}\left(X_{k}^{t}\right)$; otherwise, $X_{k}^{t+1}=X_{k}^{t+1}, \nabla J_{4 D}\left(X_{k}^{t+1}\right)=\nabla J_{4 D}\left(X_{k}^{t+1}\right)$. 
Step 7: Update the optimal flower. If $\nabla J_{4 D}\left(X_{k}^{t+1}\right)<\nabla J_{4 D}\left(X_{b}^{t}\right)$, then $X_{b}^{t}=X_{k}^{t+1}$,

$416 \nabla J_{4 D}\left(X_{b}^{t}\right)=\nabla J_{4 D}\left(X_{k}^{t+1}\right)$; otherwise, $X_{b}^{t}=X_{b}^{t}, \nabla J_{4 D}\left(X_{b}^{t}\right)=\nabla J_{4 D}\left(X_{b}^{t}\right)$.

417 Step 8: $k=k+1$. if $k<N$, then go to step 4, otherwise go to step 9.

418 Step 9: $t=t+1$. If $t<T$, then go to step 2, otherwise go to step 10 .

419 Step 10: At the end of population traversal and iterative calculation, output the optimal $420 \nabla J_{4 D}$ value and corresponding source term parameters.

421 The basic flow of gradient model optimization based on IFPA is shown in Figure 3.

\section{Simulation Case Analysis}

423 In the numerical inversion in this section, set $\boldsymbol{D}=(0.30,0.35,0.10), \boldsymbol{v}=(2,3,1), v_{d}=0.002$, $424 I=3.6, l=0.001$; the spatial step size $d x, d y$ and $d z$ are all 1 , the number of spatial steps $N=30$, 425 the time step size $d t=0.1$, and the number of time steps $M=50$; The number of hazard sources is 4263 , the coordinates are $X=[1,3,5], Y=[5,3,1], Z=3$, with the unit of $m$; the intensities of hazard sources are $Q 1=3, Q 2=5$ and $Q 3=8$ respectively, with the unit of $\mathrm{mg} / \mathrm{m}^{3}$. In this paper, the analytical solution data of 20 nodes in height $2 m$ at $t=1, t=3$ and $t=5$, which is plus $10 \%$ disturbance, are taken as the observed data. Through the improved 4DVAR algorithm, three kinds of situations such as source location known and inversion intensity, source intensity known and inversion location, source location and intensity all unknown are inversed and compared. In order to more intuitively analyze the feasibility of the algorithm in this paper, it is assumed that the background error and observation error of each observation point are in standard normal distribution in numerical simulation. The layout of observation nodes and diffusion results at each time are shown in Figure 4 and Figure 5.

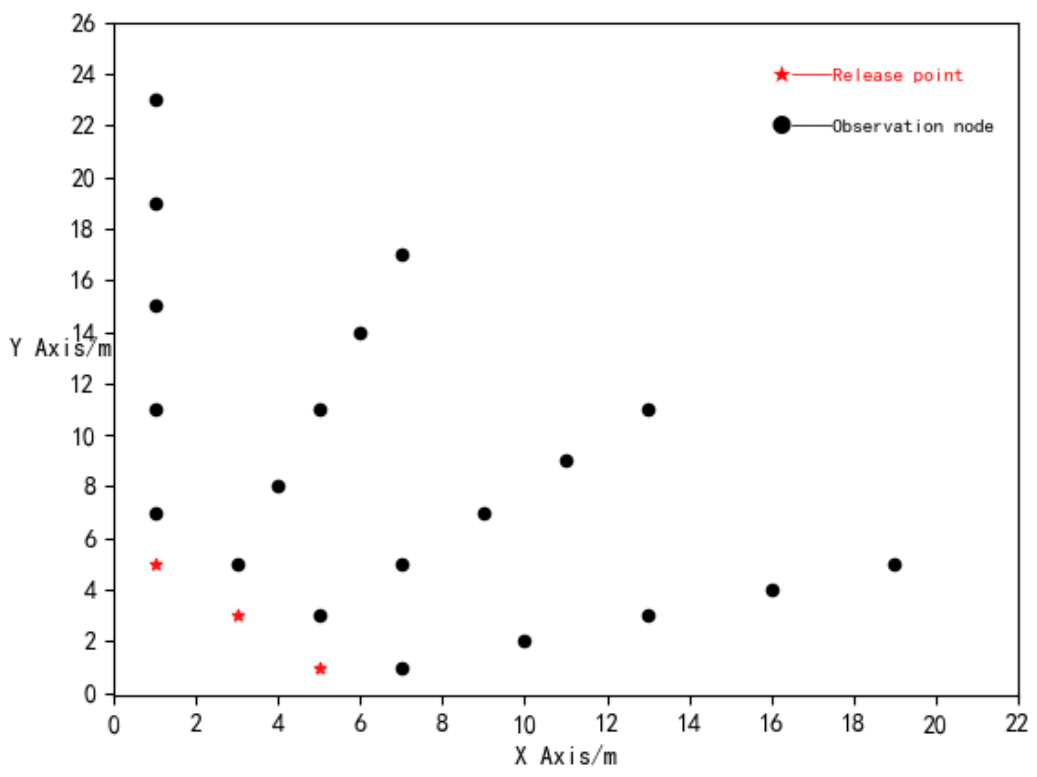



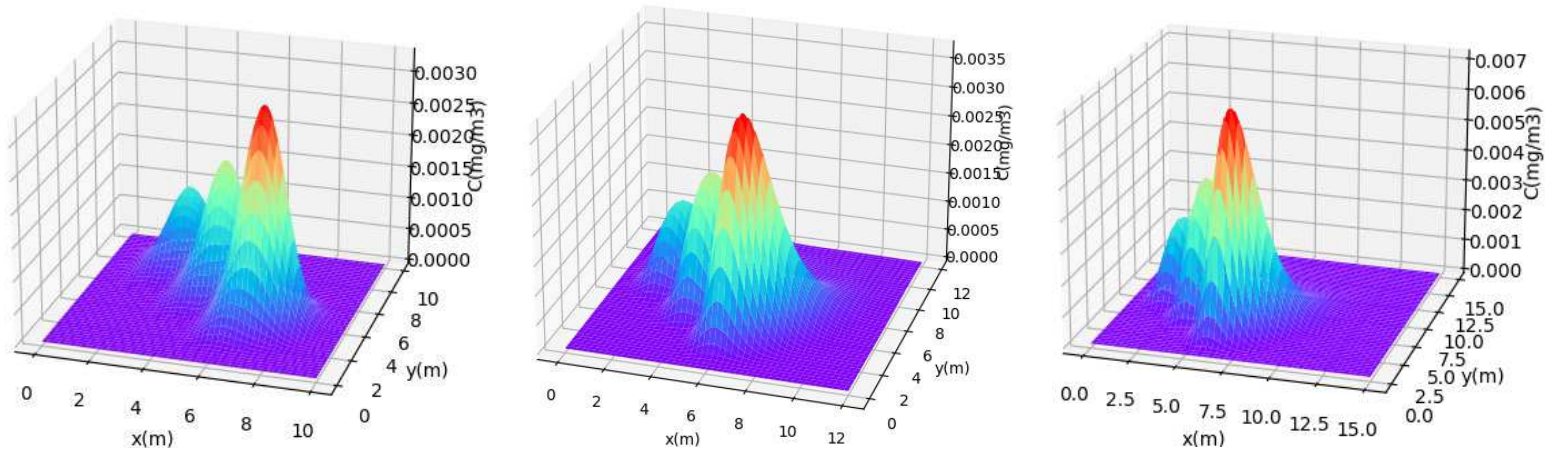

Fig.5 Simulation chart of hazard diffusion at each time

It can be seen from Figure 4 that the observation nodes are regularly distributed at equal angles and equal intervals along the downwind direction of the release point, meeting the general layout requirements of dense in front and sparse in back and uniform arrangement. It can be seen from Figure 5 that due to the influence of wind speed and diffusion parameters, the effective observed data at $t=1, t=3$ and $t=5$ are controlled within the space from the origin to $(10,10),(12,12)$ and $(15,15)$ respectively, and the layout scheme of observation nodes can cover the diffusion area of hazardous substances at each time, which shows that it is correct and applicable to use the observed data of each node under the layout scheme as the input of the improved 4DVAR algorithm. The observed data of observation nodes at each time are shown in Table 1 .

Tab. 1 Observed data of observation nodes at each time

\begin{tabular}{ccccccccccc}
\hline 节点 & 1 & 2 & 3 & 4 & 5 & 6 & 7 & 8 & 9 & 10 \\
\hline \multirow{2}{*}{$\mathrm{t}=1$} & 4.386 & 8.091 & 1.301 & 1.086 & 5.455 & 5.473 & 1.533 & 8.015 & 1.265 & 4.925 \\
& E-05 & E-05 & E-04 & E-05 & E-08 & E-04 & E-03 & E-08 & E-20 & E-08 \\
& 1.514 & 2.733 & 4.526 & 2.679 & 8.259 & 6.596 & 1.858 & 3.677 & 7.891 & 1.264 \\
$\mathrm{t}=3$ & E-04 & E-04 & E-04 & E-05 & E-07 & E-04 & E-03 & E-07 & E-10 & E-04 \\
& 2.812 & 5.075 & 8.403 & 5.006 & 1.949 & 1.390 & 3.919 & 8.311 & 2.375 & 3.481 \\
$\mathrm{t}=5$ & E-04 & E-04 & E-04 & E-05 & E-06 & E-03 & E-03 & E-07 & E-09 & E-04 \\
\hline 节点 & 11 & 12 & 13 & 14 & 15 & 16 & 17 & 18 & 19 & 20 \\
\hline \multirow{2}{*}{$\mathrm{t}=1$} & 1.349 & 7.636 & & 2.079 & 4.479 & & & & & \\
& E-07 & E-17 & 0 & E-18 & E-17 & 0 & 0 & 0 & 0 & 0 \\
$\mathrm{t}=3$ & 3.300 & 8.110 & 7.980 & 1.215 & 3.840 & 3.730 & 9.630 & 8.830 & 5.460 & 7.500 \\
& E-04 & E-10 & E-13 & E-05 & E-05 & E-12 & E-19 & E-07 & E-06 & E-16 \\
& 9.033 & 2.636 & 1.999 & 3.115 & 1.064 & 5.803 & 1.549 & 1.824 & 9.431 & 1.003 \\
$\mathrm{t}=5$ & E-04 & E-09 & E-12 & E-05 & E-04 & E-12 & E-15 & E-06 & E-06 & E-14 \\
\hline
\end{tabular}

Coordinate of observation nodes: $\mathrm{X}=[1,3,5,7,1,4,7,10,1,5,9,13,1,6,11,16,1,7,13,19]$;

$\mathrm{Y}=[7,5,3,1,11,8,5,2,15,11,7,3,19,14,9,4,23,17,11,5]$ 
Set the location data of three hazard sources as known, estimate the release intensity of each source through the improved 4DVAR algorithm. The sources intensity inversion curve is shown in Figure 6.

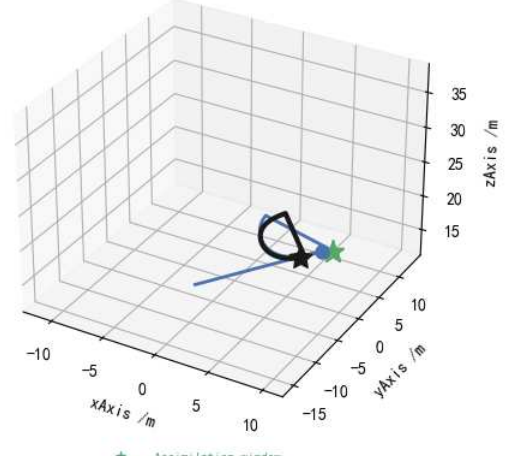

a) $t=1$

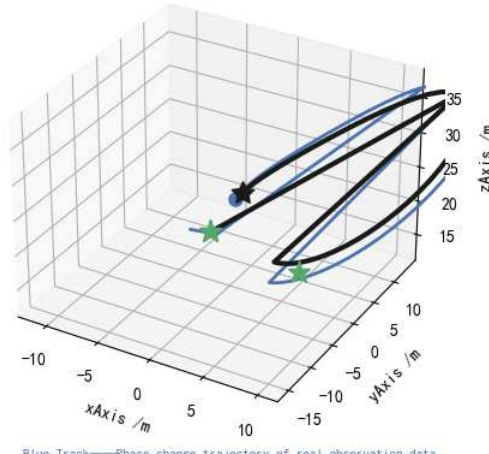

b) $t=3$

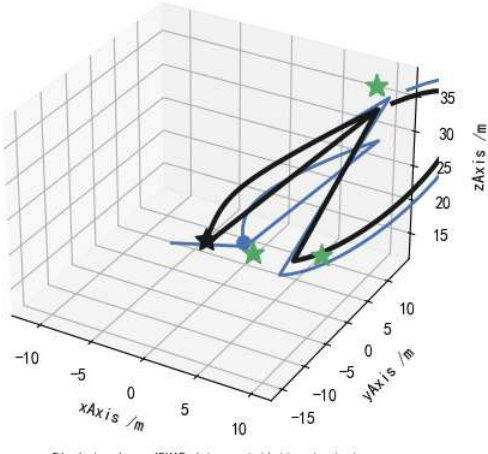

c) $t=5$

Fig.6 Inversion assimilation curve of sources intensity

In Figure 6, the green Pentagram represents an assimilation node, the blue curve represents the phase transition trajectory of observed data, the black curve represents the phase transition trajectory of predicted data after improved 4DVAR assimilation, the blue solid dot represents the final phase transition position of observed data in the assimilation window, and the black Pentagram represents the final phase transition position of predicted data in the assimilation window.

It can be seen from Figure 6 that under the condition of unknown sources intensity, the phase change trajectories of predicted data under the three assimilation windows are basically consistent with the phase change trajectories of observed data, indicating that the improved 4DVAR algorithm can better complete the data assimilation and inversion calculation according to observed data at each time. Under the time window of $t=1$, the final phase transition position of observed data basically coincides with the position of assimilation node, and there is an obvious distance between the final phase transition position of predicted data and observed data, indicating that although the disturbance effect of the first group of observed data is small, the error between predicted data and observed data after assimilation is relatively large, and there is a large gap between the inversion results and the actual situation. Under the time window of $t=3$, the final phase transition positions of predicted data and observed data basically coincide, and there is an obvious distance between the final phase transition position of observed data and assimilation node position, indicating that after the collection of the second group of observed data, the error between predicted data and observed data after assimilation is relatively small, but due to the significant disturbance effect of the second group of observed data, there is a certain gap between the inversion results and the actual situation. Under the time window 
of $t=5$, the final phase transition position of observed data is close to the position of assimilation node, and there is an obvious distance between the final phase transition position of predicted data and observed data, indicating that there is still a certain gap between the inversion results and the actual situation due to the comprehensive effects of model disturbance error, background error and observation error, but because the disturbance effect of the third group observed data is small, the inversion accuracy will be significantly improved than before.

In order to further assess the accuracy of inversion intensity, error and relative error are selected as comprehensive evaluation indexes, and the advantages and disadvantages of Kalman Filter (KF), Ensemble Kalman Filter (EnKF), 4DVAR and improved 4DVAR are analyzed. Among them, KF selects data of time $t=3$ as assimilation data. The calculation expressions of sources intensity inversion error and relative error are as follows:

$$
\left\{\begin{array}{l}
\delta_{\text {intension }}=\sqrt{\sum_{i=1}^{n}\left(Q_{i 1}-Q_{i 0}\right)^{2}} / n \\
\epsilon_{\text {intension }}=\sqrt{\sum_{i=1}^{n}\left(\frac{Q_{i 1}-Q_{i 0}}{Q_{i 0}}\right)^{2}} / n
\end{array}\right.
$$

Tab.2 Advantages and disadvantages comparison of sources intensity inversion

\begin{tabular}{lccccc}
\hline \multicolumn{1}{c}{ STI algorithm } & Intensity of No. 1 & Intensity of No. 2 & Intensity of No. 3 & $\delta_{\text {intension }}$ & $\epsilon_{\text {intension }}$ \\
\hline KF & 4.5 & 3.7 & 6.4 & 0.8498 & $19.93 \%$ \\
EnKF & 3.6 & 4.4 & 7.2 & 0.3887 & $17.38 \%$ \\
4DVAR & 3.5 & 4.5 & 7.4 & 0.3091 & $14.08 \%$ \\
Improved 4DVAR & 3.5 & 4.7 & 7.5 & 0.2560 & $6.26 \%$ \\
\hline
\end{tabular}

It can be seen from Table 2 that when the location of sources is known, EnKF, 4DVAR and improved 4DVAR can be assimilated through three groups of observed data, and KF can only be assimilated through one group of observed data. Therefore, the sources intensity estimation results of EnKF, 4DVAR and improved 4DVAR are significantly better than KF. Because 4DVAR and improved 4DVAR incorporate the numerical prediction model and tangent linear operator of convection-diffusion equation, compared with EnKF, which only assimilates and gathers the data of each observation window independently, the sources intensity estimation error can be reduced from about 0.40 before improvement to about 0.25 , and the relative error can be reduced from about $17 \%$ before improvement to about $6 \%$. At the same time, because IFPA is more global and stable than QNA, the sources intensity estimation error of improved 4DVAR is smaller and closer to the real source intensity than 4DVAR.

\subsection{Intensity known, inversion location}

Based on the analysis in Section 4.1, set the intensity data of three hazard sources as known, and use the improved 4DVAR algorithm to invert the sources location. The inversion assimilation curve of sources location is shown in Figure 7. 


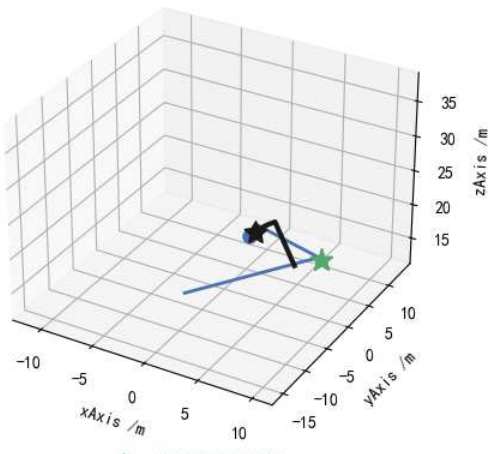

a) $t=1$

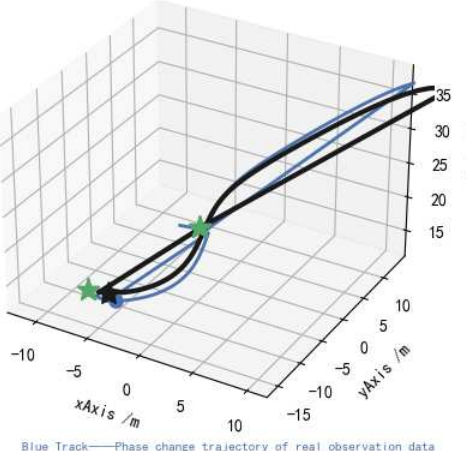

b) $t=3$

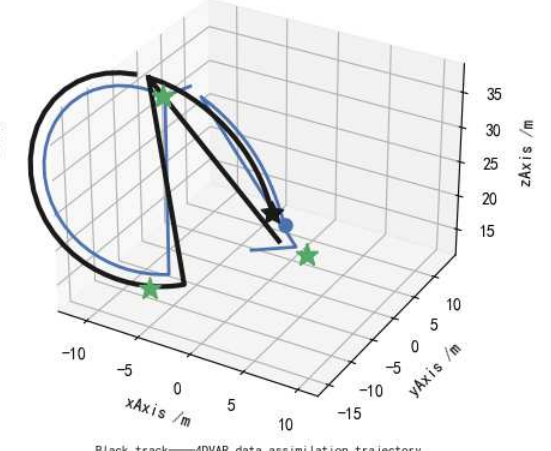

c) $t=5$
510

Fig.7 Inversion assimilation curve of sources location

It can be seen from Figure 7 that when the sources location is unknown, the phase change trajectories of predicted data under three assimilation windows are basically consistent with the phase change trajectories of observed data, indicating that in this case, the improved 4DVAR algorithm can also better complete the data assimilation and inversion calculation. The final phase transition positions of predicted data and observed data under the three assimilation windows are basically coincide or close, indicating that for the unknown variables of 9 dimensions, IFPA can better complete the optimal value search and obtain a smaller $J_{4 D}(\boldsymbol{C})$ value, which verifies the significant optimization potential of IFPA for multivariable global optimization. In addition, under the three time windows, the floating conditions of the final phase transition position of observed data and the position of assimilation node are basically consistent with Figure 6, which is caused by having the same model disturbance error, background error and observation error. The estimation result of sources location is shown in Figure 8 .

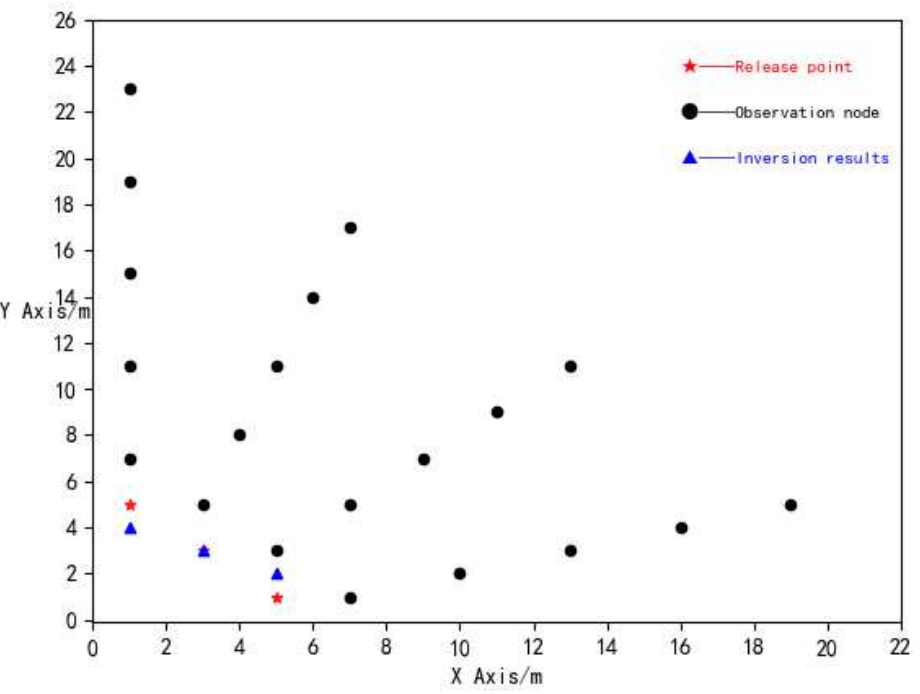

Fig. 8 Schematic diagram of sources location estimation 
in turn, where the calculation results are shown in Table 3. The calculation expressions of sources location inversion error and relative error are as follows:

$$
\left\{\begin{array}{l}
\delta_{\text {location }}=\sum_{i=1}^{n} \sqrt{\left(x_{i 1}-x_{i 0}\right)^{2}+\left(y_{i 1}-y_{i 0}\right)^{2}+\left(z_{i 1}-z_{i 0}\right)^{2}} / n \\
\epsilon_{\text {location }}=\sum_{i=1}^{n} \sqrt{\left(\frac{x_{i 1}-x_{i 0}}{x_{i 0}}\right)^{2}+\left(\frac{y_{i 1}-y_{i 0}}{y_{i 0}}\right)^{2}+\left(\frac{z_{i 1}-z_{i 0}}{z_{i 0}}\right)^{2}} / n
\end{array}\right.
$$

Tab.3 Advantages and disadvantages comparison of sources location inversion

\begin{tabular}{lccccc}
\hline \multicolumn{1}{c}{ STI algorithm } & Location of No. 1 & Location of No. 2 & Location of No. 3 & $\delta_{\text {location }}$ & $\epsilon_{\text {location }}$ \\
\hline KF & $(0,5,3)$ & $(3,3,2)$ & $(2,4,3)$ & 2.0809 & $168.65 \%$ \\
EnKF & $(0,5,3)$ & $(2,3,3)$ & $(4,2,3)$ & 1.1381 & $103.93 \%$ \\
4DVAR & $(1,4,3)$ & $(3,3,3)$ & $(5,2,4)$ & 0.8047 & $41.80 \%$ \\
Improved 4DVAR & $(1,4,3)$ & $(3,3,3)$ & $(5,2,3)$ & 0.6667 & $40.00 \%$ \\
\hline
\end{tabular}

It can be seen from Table 3 that on the basis of known source intensity, the error of KF

533 calculation result is obviously large due to too many variables and nonlinear disturbance, and 534 the error is mainly distributed in the position estimation of source No. 3. Compared with EnKF, 535 the estimation accuracy of source location by 4DVAR and improved 4DVAR is significantly 536 improved, the error can be reduced from 1.13 to 0.80 and 0.67 , and the relative error can be 537 reduced from $103.93 \%$ to about $40 \%$. Compared with 4DVAR, the accuracy of sources location 538 estimation by improved 4DVAR is not significantly improved, and the relative error difference 539 between the two is small.

$540 \quad 4.3$ Location and intensity all unknown

541 Based on the above analysis, the number, location and intensity of hazard sources are set 542 to be unknown, and the sources item information is estimated and analyzed through various 543 algorithms, as shown in Table 4.

Tab.4 Advantages and disadvantages comparison of STI

\begin{tabular}{|c|c|c|c|c|c|c|c|}
\hline STI algorithm & $\begin{array}{l}\text { No. of } \\
\text { sources }\end{array}$ & $\begin{array}{l}\text { Sources } \\
\text { location }\end{array}$ & $\begin{array}{l}\text { Sources } \\
\text { intensity }\end{array}$ & $\delta_{\text {intension }}$ & $\epsilon_{\text {intension }}$ & $\delta_{\text {location }}$ & $\epsilon_{\text {location }}$ \\
\hline $\mathrm{KF}$ & 1 & $(3,5,2)$ & 14 & - & - & - & - \\
\hline \multirow{5}{*}{ EnKF } & \multirow{5}{*}{4} & $(1,5,2)$ & 4 & \multirow{5}{*}{ - } & \multirow{5}{*}{-} & \multirow{5}{*}{-} & \multirow{5}{*}{ - } \\
\hline & & $(2,3,3)$ & 4 & & & & \\
\hline & & $(3,4,1)$ & 4 & & & & \\
\hline & & $(4,2,2)$ & 4 & & & & \\
\hline & & $(1,5,4)$ & 5 & & & & \\
\hline \multirow[t]{2}{*}{ 4DVAR } & \multirow[t]{2}{*}{3} & $(3,4,3)$ & 6 & \multirow[t]{2}{*}{0.8165} & \multirow[t]{2}{*}{$23.57 \%$} & \multirow[t]{2}{*}{1.1381} & \multirow[t]{2}{*}{$57.36 \%$} \\
\hline & & $(5,2,4)$ & 9 & & & & \\
\hline \multirow{3}{*}{$\begin{array}{c}\text { Improved } \\
\text { 4DVAR }\end{array}$} & \multirow{3}{*}{3} & $(1,5,4)$ & 4 & \multirow{3}{*}{0.4714} & \multirow{3}{*}{$11.87 \%$} & \multirow{3}{*}{1.0000} & \multirow{3}{*}{$55.56 \%$} \\
\hline & & $(3,4,3)$ & 5 & & & & \\
\hline & & $(5,2,3)$ & 7 & & & & \\
\hline
\end{tabular}
unknown, KF and EnKF have errors in sources number inversion, indicating that they have 
obvious disadvantages in multi-dimensional unknown number inversion and are difficult to meet the traceability requirements. Both 4DVAR and improved 4DVAR can retrieve the number, location and intensity of sources, which shows that the introduced numerical prediction tangent linear operator can continuously assimilate the data at three observation times, and the inversion effect is greatly improved compared with $\mathrm{KF}$ and EnKF. At the same time, compared with 4DVAR, both sources intensity inversion and sources location inversion are significantly improved, and controlled within an acceptable range, indicating that it has a good assimilation effect in multi-point sources continuous release inversion.

\section{Verification of $\mathrm{SF}_{6}$ tracer test}

On the basis of numerical simulation analysis, the algorithm is further verified by tracer test, and its adaptability and credibility in the field environment are analyzed.

\subsection{Basic information of $\mathrm{SF}_{6}$ tracer test}

From 9 a.m. to 11 a.m. on May 22, 2016, the project team conducted two atmospheric diffusion tracer tests in Xiangfang Township, Haixing County, Cangzhou City, where the tracer was $\mathrm{SF}_{6}$, the first test was used to construct the background error covariance matrix, and the second test was used to verify the algorithm in this paper. The second test is as follows: the number of release sources is two, the locations are the iron tower and next to YangCheng dam, the heights are $100 \mathrm{~m}$ and $10 \mathrm{~m}$ respectively, the release amounts are $50 \mathrm{~kg}$ and $27 \mathrm{~kg}$ respectively, and the release time is $40 \mathrm{~min}$. During the test, the dominant wind direction is northeast wind, and the atmospheric stability is DDC.

The space of the experimental site was about $10 \mathrm{~km} \times 7 \mathrm{~km}$, a total of 4 fixed meteorological stations, 20 portable meteorological observation points and 50 fan-shaped concentration sampling points were set up to observe the data such as wind speed, temperature, humidity, air pressure and tracer concentration in real time, as shown in Figure 9. The sampling time interval was $10 \mathrm{~min}$ and $\mathrm{SF}_{6}$ samples were taken three times for each test, which were collected and analyzed by EM-1500 Portable Gas Sampler, LB-201-4L Aluminum Foil Sampling Bag and 


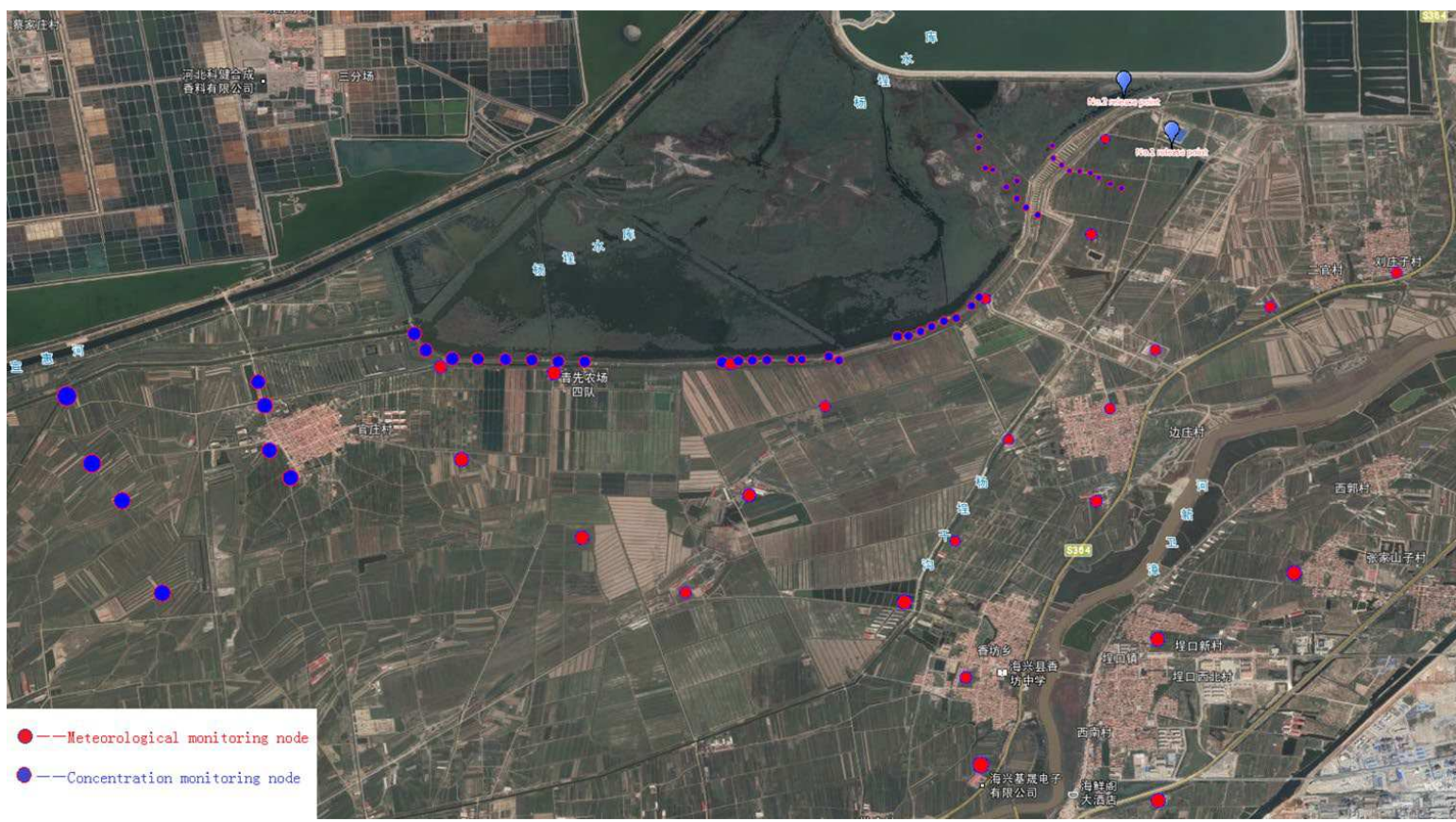

Fig.9 Layout of release points and monitoring nodes

According to the data collected by fixed meteorological stations and portable meteorological observation points, the initial boundary conditions and wind field information of diffusion space are constructed based on WRF wind field diagnosis model. To make the calculations and the analyses convenient, East Longitude 117.636781-117.755706 and North Latitude 38.091503-38.154587 are taken as the four boundary points of coordinate axis, $(117.636781,38.091503)$ is taken as the origin of coordinate axis, due East direction is set as the positive direction of $\mathrm{X}$ axis, due North direction is set as the positive direction of $\mathrm{Y}$ axis, ground vertical upward direction is set as the positive direction of $\mathrm{Z}$ axis, and the longitude and latitude information of each point is converted to three-dimensional spatial coordinates, where the initial boundary conditions are set as shown in Table 5, the ground wind field information during the experiment is shown in Figure 10.

\begin{tabular}{|c|c|c|c|c|}
\hline Parameter & Direction / Position & Properties & Connotation & Parameter value \\
\hline Wind speed & northeasterly wind & air inlet & simulate natural wind & $\begin{array}{c}\text { wind direction } 204^{\circ} \\
\text { average wind speed } 5.5 \mathrm{~m} / \mathrm{s}\end{array}$ \\
\hline External air pressure & $\begin{array}{l}\mathrm{X} \text { negative axis } \\
\text { direction }\end{array}$ & air outlet & $\begin{array}{c}\text { analog air pressure } \\
\text { outlet }\end{array}$ & 1019.2hpa \\
\hline $\begin{array}{l}\text { Release source } \\
\text { coordinates }\end{array}$ & $\begin{array}{l}\text { iron tower } \\
\text { dam }\end{array}$ & $\begin{array}{l}\text { release source } \\
\text { location }\end{array}$ & simulate release point & $\begin{array}{l}(8406,6322,100) \\
(8061,6874,10)\end{array}$ \\
\hline $\begin{array}{l}\text { Release source } \\
\text { information }\end{array}$ & $\begin{array}{l}\mathrm{Z} \text { positive axis } \\
\text { direction }\end{array}$ & $\mathrm{SF}_{6}$ inlet & $\begin{array}{l}\text { simulate } \mathrm{SF}_{6} \\
\text { emissions }\end{array}$ & $\begin{array}{l}20.83 \mathrm{~g} / \mathrm{s}, 40 \mathrm{~min} \\
8.98 \mathrm{~g} / \mathrm{s}, 40 \mathrm{~min}\end{array}$ \\
\hline $\begin{array}{l}\text { Turbulence } \\
\text { information }\end{array}$ & $\begin{array}{l}\mathrm{X} \text { positive axis } \\
\text { direction }\end{array}$ & $\begin{array}{l}\text { turbulent inlet } \\
\text { and outlet }\end{array}$ & turbulence intensity & $4.02 \%, 4.15 \%$ \\
\hline
\end{tabular}




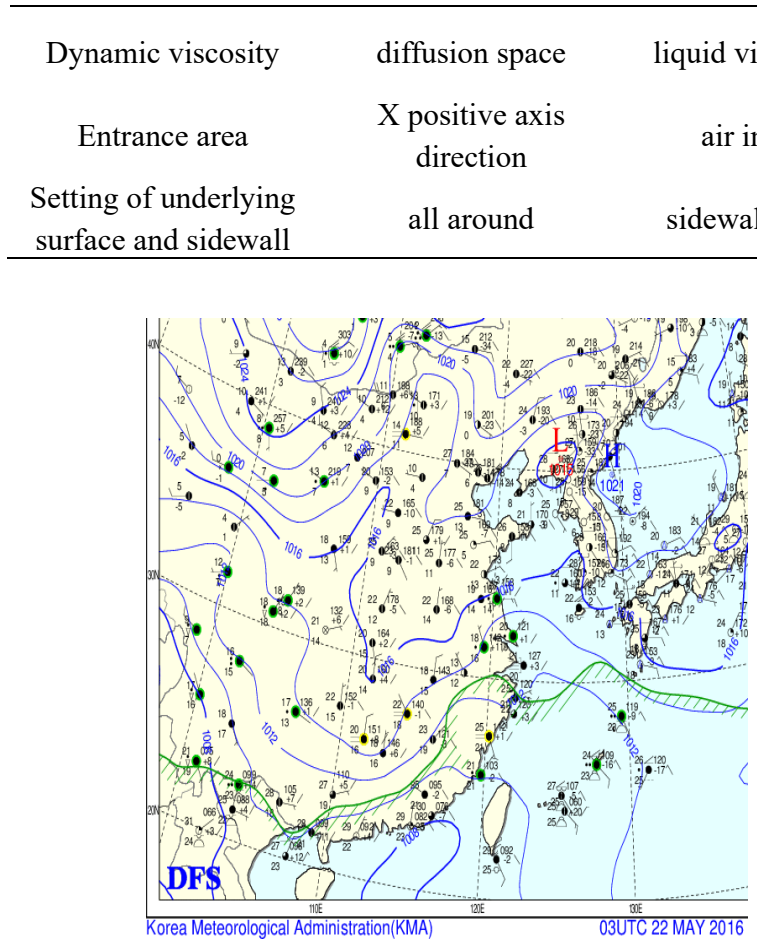

(a) Ground weather situation
$0.0000142 \mathrm{~Pa} \cdot \mathrm{s}$

$50 m \times 50 m$

$10 \mathrm{~km} \times 10 \mathrm{~km} \times 0.2 \mathrm{~km}$ simulate underlying surface and sidewall

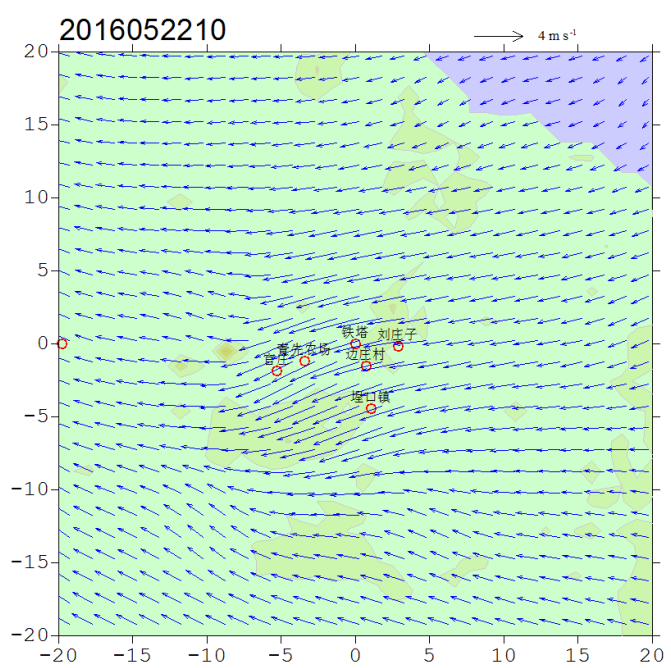

(b) Change of ground wind field

Fig.10 Wind field construction of diffusion space

5.2 Experimental simulation and analysis

5.2.1 Experimental parameter setting

Use the improved 4DVAR algorithm to inverse the whole diffusion process. The experimental parameters are set as follows: the number, location and intensity of sources are set unknown; the spatial steps $d x, d y$ and $d z$ are all 10, and the spatial steps are 1000, 1000 and 20 respectively; time steps $d t=10$, number of time steps $M=180 ; \sigma_{x}, \sigma_{y}$ and $\sigma_{z}$ is obtained from $P-G$ diffusion curve; dry and wet sedimentation is not considered; the observation operator is the identity matrix; flower population size $N=200$, pollination mode conversion probability $P=0.8$, maximum iteration times $T=500$. Since the sampling equipment and analysis equipment at each observation point are the same, the comprehensive error variance of the sampling equipment and analysis equipment is taken as the diagonal element of the observation error covariance matrix.

\subsubsection{Calculation of STI}

Based on the setting of experimental parameters, according to the improved 4DVAR solution and inversion process, the tracer diffusion test is calculated and simulated to solve the number, location and intensity of sources under $\nabla J_{4 D}\left(c_{0}\right)$ minimum. Since only 42 nodes monitored $\mathrm{SF}_{6}$ concentration data during the test, the observed data of these 42 nodes were used for data assimilation. The optimization assimilation curve of STI is shown in Figure 11, and the results are shown in Table 6. 


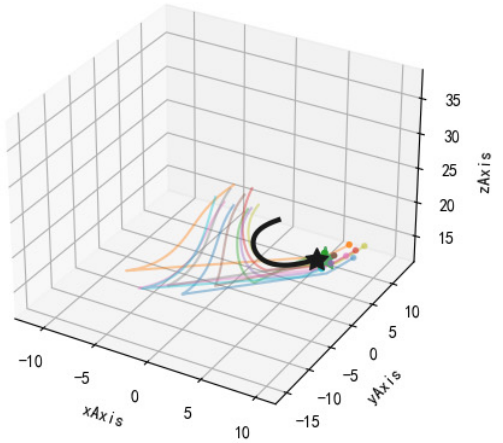

610

611

612

613

614

615

616 basically tended to the optimal solution.

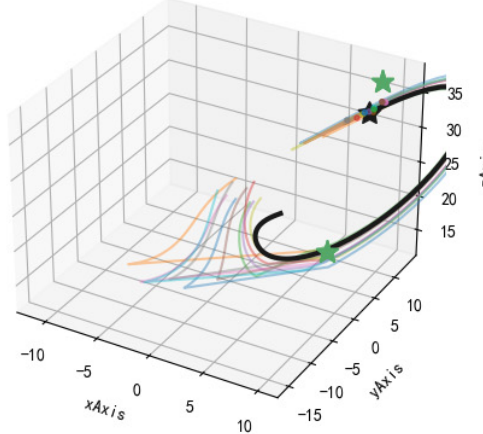

(b) $t=20 \mathrm{~min}$

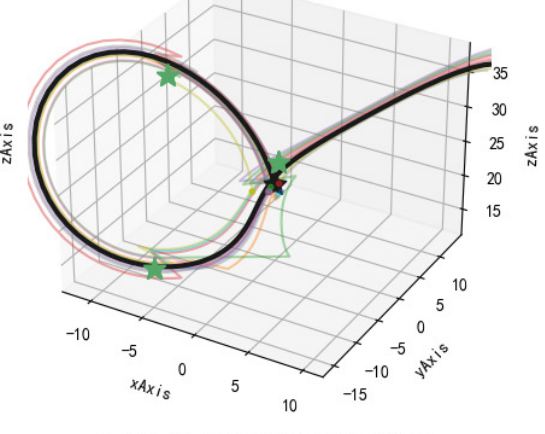

(c) $t=30 \mathrm{~min}$

Fig.11 STI optimization assimilation curve

It can be seen from Figure 11 (a) that the first group of observation data has obvious discreteness and randomness. There is an obvious difference between the phase transition trajectory of prediction data and observation data, but the final phase transition positions of predicted data and observed data basically coincides, which verifies the stability and convergence of the improved 4DVAR algorithm. It can be seen from Figure 11 (b) that the phase change trajectory of predicted data in second time window is basically consistent with that of observed data, but there is a certain distance between the final phase transition positions of predicted data and observed data, which shows that the improved 4DVAR algorithm can quickly adjust the update mode and mutation operation. As can be seen from Figure 11 (c), under the third time window, the phase transition trajectory of predicted data is basically consistent with that of observed data, and the final phase transition positions of predicted data and observed data is basically close, indicating that after three times of data assimilation, $\nabla J_{4 D}\left(c_{0}\right)$ has

Tab.6 STI results based on improved 4DVAR

\begin{tabular}{cccccccc}
\hline STI algorithm & No. of sources & Sources location & Sources intensity & $\delta_{\text {intension }}$ & $\epsilon_{\text {intension }}$ & $\delta_{\text {location }}$ & $\epsilon_{\text {location }}$ \\
\hline Improved & 2 & $(8697,6478,60)$ & $20.54 \mathrm{~g} / \mathrm{s}$ & \multirow{2}{*}{3.3232} & $36.98 \%$ & 271.8383 & $170.12 \%$ \\
4DVAR & 2 & $(8160,6690,40)$ & $15.62 \mathrm{~g} / \mathrm{s}$ & & & & \\
\hline
\end{tabular}

It can be seen from Table 6 that the relative error of sources intensity is $36.98 \%$, and the relative error of sources location is $170.12 \%$, which basically meets the actual demand for sources seeking. In practical work, on this basis, active accurate traceability can be carried out through on-site reconnaissance or UAV search.

In order to better analyze the assimilation performance of improved 4DVAR algorithm, on the basis of STI, the predicted data by analytical solution, predicted data by improved 4DVAR assimilation and real observed data are compared, as shown in Table 7 and Figure 12. The calculation expression of concentration difference is: 


$$
\left\{\begin{array}{l}
d_{1}=\left|c_{1}-c_{3}\right| / c_{3} \\
d_{2}=\left|c_{2}-c_{3}\right| / c_{3} \\
d_{3}=d_{2}-d_{1}
\end{array}\right.
$$

Where, $c_{1}$ is the predicted concentration value by analytical solution; $c_{2}$ is the predicted concentration value by improved 4DVAR assimilation; $c_{3}$ is the real observed concentration value; $d_{1}$ is the difference between $c_{1}$ and $c_{3} ; d_{2}$ is the difference between $c_{2}$ and $c_{3} ; d_{3}$ 639 is the increased degree of concentration prediction accuracy of 4DVAR assimilation relative to 640 analytical solution.
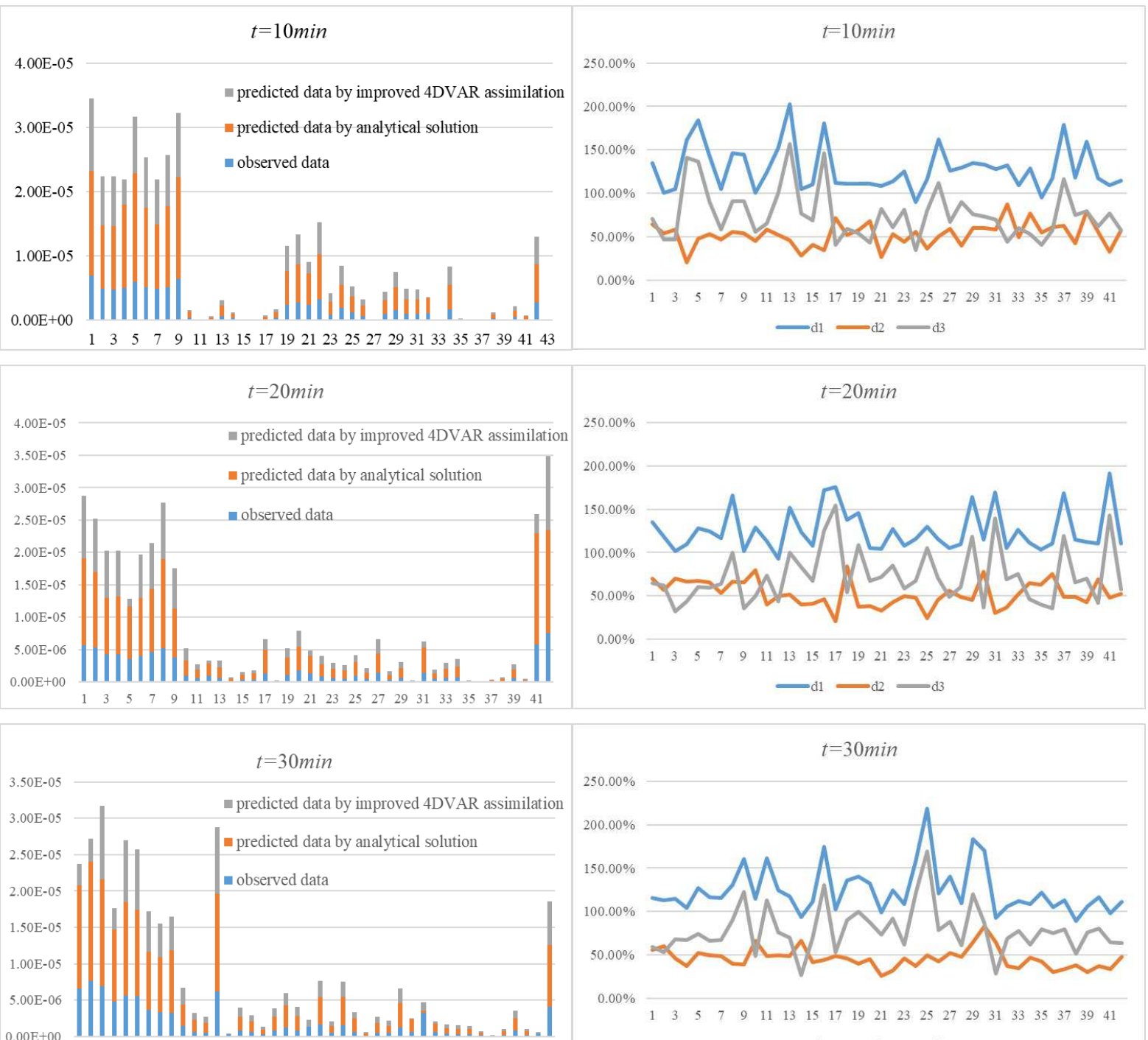

(a) Concentration data analysis

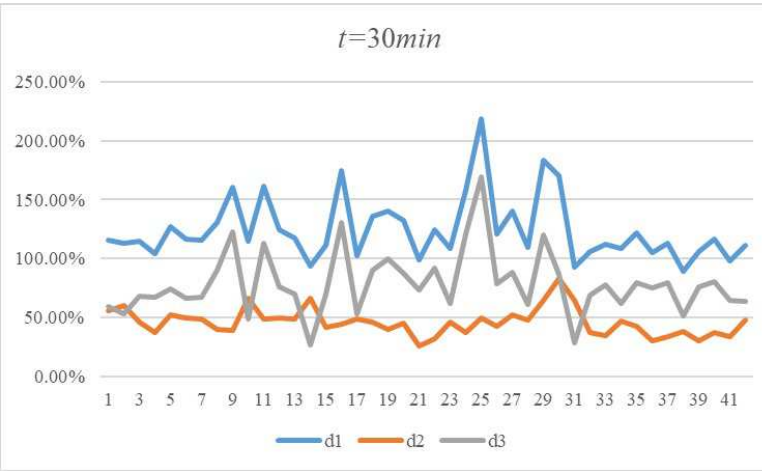

Fig.12 Comparative analysis of predicted data by analytical solution, predicted data by 
Tab. 7 Results comparison of predicted data by analytical solution, predicted data by improved 4DVAR assimilation and real observed data

\begin{tabular}{|c|c|c|c|c|c|c|c|c|c|c|c|c|c|}
\hline \multirow{2}{*}{$\begin{array}{c}\text { Monitoring } \\
\text { nodes }\end{array}$} & \multicolumn{6}{|c|}{$10 \mathrm{~min}$} & \multirow{2}{*}{$\begin{array}{l}\text { Monitoring } \\
\text { nodes }\end{array}$} & \multicolumn{6}{|c|}{$10 \mathrm{~min}$} \\
\hline & $\mathrm{c}_{1} /\left(\mathrm{kg} / \mathrm{m}^{3}\right)$ & $\mathrm{c}_{2} /\left(\mathrm{kg} / \mathrm{m}^{3}\right)$ & $\mathrm{c}_{3} /\left(\mathrm{kg} / \mathrm{m}^{3}\right)$ & $d_{1} / \%$ & $\mathrm{~d}_{2} / \%$ & $\mathrm{~d}_{3} / \%$ & & $\mathrm{c}_{1} /\left(\mathrm{kg} / \mathrm{m}^{3}\right)$ & $\mathrm{c}_{2} /\left(\mathrm{kg} / \mathrm{m}^{3}\right)$ & $\mathrm{c}_{3} /\left(\mathrm{kg} / \mathrm{m}^{3}\right)$ & $\mathrm{d}_{1} / \%$ & $\mathrm{~d}_{2} / \%$ & $\mathrm{~d}_{3} / \%$ \\
\hline 1 & $1.62 \mathrm{E}-05$ & $1.14 \mathrm{E}-05$ & $6.92 \mathrm{E}-06$ & 134.82 & 64.45 & 70.36 & 22 & $6.98 \mathrm{E}-06$ & 4.99E-06 & $3.27 \mathrm{E}-06$ & 113.45 & 52.67 & 60.79 \\
\hline 2 & $9.88 \mathrm{E}-06$ & 7.59E-06 & 4.93E-06 & 100.47 & 54.06 & 46.41 & 23 & $1.99 \mathrm{E}-06$ & $1.27 \mathrm{E}-06$ & $8.85 \mathrm{E}-07$ & 124.72 & 43.98 & 80.74 \\
\hline 3 & $9.88 \mathrm{E}-06$ & 7.64E-06 & 4.83E-06 & 104.59 & 58.29 & 46.30 & 24 & $3.63 \mathrm{E}-06$ & 2.97E-06 & $1.92 \mathrm{E}-06$ & 89.56 & 55.10 & 34.46 \\
\hline 4 & $1.30 \mathrm{E}-05$ & $3.95 \mathrm{E}-06$ & 4.97E-06 & 161.12 & 20.55 & 140.57 & 25 & $2.50 \mathrm{E}-06$ & $1.57 \mathrm{E}-06$ & $1.16 \mathrm{E}-06$ & 115.97 & 35.83 & 80.14 \\
\hline 5 & $1.69 \mathrm{E}-05$ & 8.79E-06 & $5.95 \mathrm{E}-06$ & 183.97 & 47.61 & 136.36 & 26 & $1.63 \mathrm{E}-06$ & $9.38 \mathrm{E}-07$ & $6.23 \mathrm{E}-07$ & 162.17 & 50.45 & 111.73 \\
\hline 6 & $1.24 \mathrm{E}-05$ & $7.81 \mathrm{E}-06$ & $5.12 \mathrm{E}-06$ & 142.32 & 52.44 & 89.87 & 27 & $1.76 \mathrm{E}-08$ & $1.24 \mathrm{E}-08$ & 7.79E-09 & 125.67 & 58.77 & 66.90 \\
\hline 7 & 9.97E-06 & 7.12E-06 & 4.87E-06 & 104.83 & 46.33 & 58.49 & 28 & 2.19E-06 & $1.33 \mathrm{E}-06$ & $9.56 \mathrm{E}-07$ & 129.28 & 39.65 & 89.63 \\
\hline 8 & $1.26 \mathrm{E}-05$ & 7.97E-06 & $5.13 \mathrm{E}-06$ & 146.10 & 55.35 & 90.76 & 29 & $3.59 \mathrm{E}-06$ & $2.44 \mathrm{E}-06$ & $1.53 \mathrm{E}-06$ & 134.83 & 59.49 & 75.34 \\
\hline 9 & $1.58 \mathrm{E}-05$ & $9.95 \mathrm{E}-06$ & $6.46 \mathrm{E}-06$ & 144.36 & 54.00 & 90.36 & 30 & $2.30 \mathrm{E}-06$ & $1.58 \mathrm{E}-06$ & $9.86 \mathrm{E}-07$ & 133.05 & 60.15 & 72.90 \\
\hline 10 & $8.68 \mathrm{E}-07$ & 2.39E-07 & 4.33E-07 & 100.51 & 44.78 & 55.73 & 31 & 2.27E-06 & $1.57 \mathrm{E}-06$ & 9.94E-07 & 128.15 & 58.36 & 69.79 \\
\hline 11 & $1.87 \mathrm{E}-08$ & $1.33 \mathrm{E}-08$ & 8.37E-09 & 123.89 & 58.37 & 65.53 & 32 & $2.45 \mathrm{E}-06$ & $1.31 \mathrm{E}-07$ & $1.06 \mathrm{E}-06$ & 132.02 & 87.64 & 44.39 \\
\hline 12 & $2.94 \mathrm{E}-07$ & $1.77 \mathrm{E}-07$ & $1.16 \mathrm{E}-07$ & 152.11 & 51.99 & 100.12 & 33 & 4.80E-08 & $3.42 \mathrm{E}-08$ & $2.29 \mathrm{E}-08$ & 109.61 & 49.50 & 60.11 \\
\hline 13 & $1.72 \mathrm{E}-06$ & 8.29E-07 & $5.69 \mathrm{E}-07$ & 202.63 & 45.81 & 156.82 & 34 & $3.80 \mathrm{E}-06$ & $2.93 \mathrm{E}-06$ & $1.66 \mathrm{E}-06$ & 128.78 & 76.33 & 52.46 \\
\hline 14 & $6.85 \mathrm{E}-07$ & $2.39 \mathrm{E}-07$ & $3.34 \mathrm{E}-07$ & 104.98 & 28.44 & 76.54 & 35 & 9.09E-08 & $7.21 \mathrm{E}-08$ & 4.67E-08 & 94.72 & 54.28 & 40.44 \\
\hline 15 & $5.10 \mathrm{E}-08$ & $3.42 \mathrm{E}-08$ & $2.43 \mathrm{E}-08$ & 110.00 & 40.91 & 69.09 & 36 & 2.09E-08 & $1.54 \mathrm{E}-08$ & $9.63 \mathrm{E}-09$ & 117.30 & 60.38 & 56.92 \\
\hline 16 & $1.83 \mathrm{E}-08$ & 8.78E-09 & $6.52 \mathrm{E}-09$ & 180.74 & 34.66 & 146.07 & 37 & $2.26 \mathrm{E}-08$ & $1.32 \mathrm{E}-08$ & $8.11 \mathrm{E}-09$ & 178.94 & 62.33 & 116.61 \\
\hline 17 & 2.99E-07 & $2.41 \mathrm{E}-07$ & $1.41 \mathrm{E}-07$ & 112.03 & 71.17 & 40.86 & 38 & $5.68 \mathrm{E}-07$ & $3.71 \mathrm{E}-07$ & $2.61 \mathrm{E}-07$ & 117.63 & 42.33 & 75.29 \\
\hline 18 & $7.82 \mathrm{E}-07$ & $5.63 \mathrm{E}-07$ & $3.71 \mathrm{E}-07$ & 110.79 & 51.76 & 59.03 & 39 & $2.62 \mathrm{E}-08$ & $1.82 \mathrm{E}-08$ & $1.01 \mathrm{E}-08$ & 159.41 & 79.70 & 79.70 \\
\hline 19 & 5.19E-06 & $3.87 \mathrm{E}-06$ & $2.46 \mathrm{E}-06$ & 111.23 & 57.33 & 53.90 & 40 & $9.66 \mathrm{E}-07$ & $6.92 \mathrm{E}-07$ & $4.45 \mathrm{E}-07$ & 116.99 & 55.51 & 61.48 \\
\hline 20 & $5.90 \mathrm{E}-06$ & 4.70E-06 & $2.80 \mathrm{E}-06$ & 110.71 & 67.86 & 42.86 & 41 & $4.10 \mathrm{E}-07$ & $1.32 \mathrm{E}-07$ & $1.96 \mathrm{E}-07$ & 109.35 & 32.79 & 76.56 \\
\hline 21 & 4.91E-06 & 1.74E-06 & 2.36E-06 & 108.17 & 26.37 & 81.80 & 42 & 5.93E-06 & 4.34E-06 & $2.76 \mathrm{E}-06$ & 114.55 & 57.24 & 57.31 \\
\hline
\end{tabular}




\begin{tabular}{|c|c|c|c|c|c|c|c|c|c|c|c|c|c|}
\hline \multirow{2}{*}{$\begin{array}{l}\text { Monitoring } \\
\text { nodes }\end{array}$} & \multicolumn{6}{|c|}{$20 \mathrm{~min}$} & \multirow{2}{*}{$\begin{array}{c}\text { Monitoring } \\
\text { nodes }\end{array}$} & \multicolumn{6}{|c|}{$20 \mathrm{~min}$} \\
\hline & $\mathrm{c}_{1} /\left(\mathrm{kg} / \mathrm{m}^{3}\right)$ & $\mathrm{c}_{2} /\left(\mathrm{kg} / \mathrm{m}^{3}\right)$ & $\mathrm{c}_{3} /\left(\mathrm{kg} / \mathrm{m}^{3}\right)$ & $\mathrm{d}_{1} / \%$ & $\mathrm{~d}_{2} / \%$ & $\mathrm{~d}_{3} / \%$ & & $\mathrm{c}_{1} /\left(\mathrm{kg} / \mathrm{m}^{3}\right)$ & $\mathrm{c}_{2} /\left(\mathrm{kg} / \mathrm{m}^{3}\right)$ & $\mathrm{c}_{3} /\left(\mathrm{kg} / \mathrm{m}^{3}\right)$ & $\mathrm{d}_{1} / \%$ & $\mathrm{~d}_{2} / \%$ & $\mathrm{~d}_{3} / \%$ \\
\hline 1 & $1.34 \mathrm{E}-05$ & $9.69 \mathrm{E}-06$ & $5.69 \mathrm{E}-06$ & 135.17 & 70.33 & 64.83 & 22 & $1.92 \mathrm{E}-06$ & $1.21 \mathrm{E}-06$ & $8.46 \mathrm{E}-07$ & 127.46 & 42.88 & 84.58 \\
\hline 2 & $1.16 \mathrm{E}-05$ & $8.32 \mathrm{E}-06$ & $5.32 \mathrm{E}-06$ & 118.80 & 56.39 & 62.40 & 23 & $1.38 \mathrm{E}-06$ & $9.91 \mathrm{E}-07$ & $6.61 \mathrm{E}-07$ & 107.93 & 49.78 & 58.15 \\
\hline 3 & $8.69 \mathrm{E}-06$ & $7.31 \mathrm{E}-06$ & $4.31 \mathrm{E}-06$ & 101.61 & 69.62 & 31.99 & 24 & $1.20 \mathrm{E}-06$ & $8.22 \mathrm{E}-07$ & $5.55 \mathrm{E}-07$ & 115.54 & 48.13 & 67.40 \\
\hline 4 & $8.95 \mathrm{E}-06$ & $7.10 \mathrm{E}-06$ & $4.28 \mathrm{E}-06$ & 109.36 & 66.12 & 43.23 & 25 & $2.13 \mathrm{E}-06$ & $1.15 \mathrm{E}-06$ & $9.28 \mathrm{E}-07$ & 129.39 & 23.93 & 105.47 \\
\hline 5 & $8.11 \mathrm{E}-06$ & $1.15 \mathrm{E}-06$ & $3.56 \mathrm{E}-06$ & 128.12 & 67.62 & 60.49 & 26 & $9.85 \mathrm{E}-07$ & $6.64 \mathrm{E}-07$ & $4.56 \mathrm{E}-07$ & 115.87 & 45.47 & 70.40 \\
\hline 6 & $9.01 \mathrm{E}-06$ & $6.63 \mathrm{E}-06$ & $4.00 \mathrm{E}-06$ & 124.97 & 65.49 & 59.48 & 27 & $2.97 \mathrm{E}-06$ & $2.26 \mathrm{E}-06$ & $1.45 \mathrm{E}-06$ & 104.93 & 56.12 & 48.81 \\
\hline 7 & $9.88 \mathrm{E}-06$ & 6.99E-06 & $4.56 \mathrm{E}-06$ & 116.69 & 53.21 & 63.48 & 28 & $7.59 \mathrm{E}-07$ & 5.39E-07 & $3.63 \mathrm{E}-07$ & 109.18 & 48.56 & 60.62 \\
\hline 8 & $1.38 \mathrm{E}-05$ & $8.62 \mathrm{E}-06$ & $5.19 \mathrm{E}-06$ & 166.31 & 66.05 & 100.26 & 29 & $1.58 \mathrm{E}-06$ & $8.70 \mathrm{E}-07$ & $5.98 \mathrm{E}-07$ & 164.08 & 45.51 & 118.57 \\
\hline 9 & $7.58 \mathrm{E}-06$ & $6.24 \mathrm{E}-06$ & $3.76 \mathrm{E}-06$ & 101.56 & 65.78 & 35.78 & 30 & $5.84 \mathrm{E}-08$ & 4.84E-08 & 2.72E-08 & 115.10 & 78.29 & 36.81 \\
\hline 10 & $2.33 \mathrm{E}-06$ & $1.83 \mathrm{E}-06$ & $1.02 \mathrm{E}-06$ & 129.33 & 79.82 & 49.51 & 31 & $3.86 \mathrm{E}-06$ & $9.94 \mathrm{E}-07$ & $1.43 \mathrm{E}-06$ & 169.89 & 30.54 & 139.35 \\
\hline 11 & $1.31 \mathrm{E}-06$ & $8.60 \mathrm{E}-07$ & $6.16 \mathrm{E}-07$ & 112.84 & 39.71 & 73.13 & 32 & $9.13 \mathrm{E}-07$ & $6.07 \mathrm{E}-07$ & $4.46 \mathrm{E}-07$ & 104.96 & 36.30 & 68.66 \\
\hline 12 & $1.86 \mathrm{E}-06$ & $4.90 \mathrm{E}-07$ & $9.67 \mathrm{E}-07$ & 92.76 & 49.31 & 43.45 & 33 & $1.41 \mathrm{E}-06$ & $9.37 \mathrm{E}-07$ & $6.20 \mathrm{E}-07$ & 126.53 & 51.07 & 75.45 \\
\hline 13 & $1.65 \mathrm{E}-06$ & $9.93 \mathrm{E}-07$ & $6.55 \mathrm{E}-07$ & 151.45 & 51.53 & 99.92 & 34 & $1.60 \mathrm{E}-06$ & $1.25 \mathrm{E}-06$ & $7.56 \mathrm{E}-07$ & 110.96 & 64.81 & 46.14 \\
\hline 14 & $3.40 \mathrm{E}-07$ & $2.13 \mathrm{E}-07$ & $1.52 \mathrm{E}-07$ & 123.40 & 40.27 & 83.13 & 35 & $8.81 \mathrm{E}-08$ & $7.06 \mathrm{E}-08$ & 4.32E-08 & 103.64 & 63.24 & 40.40 \\
\hline 15 & $7.41 \mathrm{E}-07$ & $5.01 \mathrm{E}-07$ & $3.56 \mathrm{E}-07$ & 108.20 & 40.72 & 67.48 & 36 & $5.05 \mathrm{E}-08$ & $4.20 \mathrm{E}-08$ & $2.40 \mathrm{E}-08$ & 110.36 & 74.99 & 35.37 \\
\hline 16 & $9.45 \mathrm{E}-07$ & $5.08 \mathrm{E}-07$ & $3.47 \mathrm{E}-07$ & 172.03 & 46.43 & 125.61 & 37 & $1.80 \mathrm{E}-07$ & $1.00 \mathrm{E}-07$ & $6.73 \mathrm{E}-08$ & 168.25 & 49.15 & 119.09 \\
\hline 17 & $3.65 \mathrm{E}-06$ & $1.60 \mathrm{E}-06$ & $1.33 \mathrm{E}-06$ & 175.43 & 20.51 & 154.92 & 38 & $3.24 \mathrm{E}-07$ & $2.25 \mathrm{E}-07$ & $1.51 \mathrm{E}-07$ & 114.56 & 48.81 & 65.75 \\
\hline 18 & $1.35 \mathrm{E}-07$ & $1.04 \mathrm{E}-07$ & $5.67 \mathrm{E}-08$ & 137.68 & 83.88 & 53.80 & 39 & $1.26 \mathrm{E}-06$ & $8.48 \mathrm{E}-07$ & $5.96 \mathrm{E}-07$ & 112.07 & 42.28 & 69.79 \\
\hline 19 & $2.66 \mathrm{E}-06$ & $1.48 \mathrm{E}-06$ & $1.08 \mathrm{E}-06$ & 145.98 & 36.97 & 109.01 & 40 & $1.99 \mathrm{E}-07$ & $1.60 \mathrm{E}-07$ & $9.43 \mathrm{E}-08$ & 110.60 & 69.21 & 41.39 \\
\hline 20 & $3.66 \mathrm{E}-06$ & $2.46 \mathrm{E}-06$ & $1.78 \mathrm{E}-06$ & 105.36 & 38.12 & 67.23 & 41 & $1.71 \mathrm{E}-05$ & $3.02 \mathrm{E}-06$ & $5.85 \mathrm{E}-06$ & 191.65 & 48.34 & 143.31 \\
\hline 21 & $2.70 \mathrm{E}-06$ & 8.91E-07 & $1.32 \mathrm{E}-06$ & 104.34 & 32.58 & 71.76 & 42 & $1.59 \mathrm{E}-05$ & $1.15 \mathrm{E}-05$ & $7.54 \mathrm{E}-06$ & 110.35 & 52.56 & 57.79 \\
\hline
\end{tabular}




\begin{tabular}{|c|c|c|c|c|c|c|c|c|c|c|c|c|c|}
\hline \multirow{2}{*}{$\begin{array}{l}\text { Monitoring } \\
\text { nodes }\end{array}$} & \multicolumn{6}{|c|}{$30 \mathrm{~min}$} & \multirow{2}{*}{$\begin{array}{l}\text { Monitoring } \\
\text { nodes }\end{array}$} & \multicolumn{6}{|c|}{$30 \mathrm{~min}$} \\
\hline & $\mathrm{c}_{1} /\left(\mathrm{g} / \mathrm{m}^{3}\right)$ & $\mathrm{c}_{2} /\left(\mathrm{g} / \mathrm{m}^{3}\right)$ & $\mathrm{c}_{3} /\left(\mathrm{g} / \mathrm{m}^{3}\right)$ & $\mathrm{d}_{1} / \%$ & $\mathrm{~d}_{2} / \%$ & $\mathrm{~d}_{3} / \%$ & & $\mathrm{c}_{1} /\left(\mathrm{g} / \mathrm{m}^{3}\right)$ & $\mathrm{c}_{2} /\left(\mathrm{g} / \mathrm{m}^{3}\right)$ & $\mathrm{c}_{3} /\left(\mathrm{g} / \mathrm{m}^{3}\right)$ & $\mathrm{d}_{1} / \%$ & $\mathrm{~d}_{2} / \%$ & $\mathrm{~d}_{3} / \%$ \\
\hline 1 & $1.42 \mathrm{E}-05$ & $2.90 \mathrm{E}-06$ & $6.60 \mathrm{E}-06$ & 115.15 & 56.04 & 59.11 & 22 & $3.75 \mathrm{E}-06$ & $2.21 \mathrm{E}-06$ & $1.67 \mathrm{E}-06$ & 124.24 & 32.08 & 92.17 \\
\hline 2 & $1.64 \mathrm{E}-05$ & $3.08 \mathrm{E}-06$ & 7.69E-06 & 113.00 & 59.96 & 53.04 & 23 & $9.64 \mathrm{E}-07$ & $6.78 \mathrm{E}-07$ & 4.63E-07 & 108.06 & 46.36 & 61.70 \\
\hline 3 & $1.47 \mathrm{E}-05$ & $1.01 \mathrm{E}-05$ & $6.87 \mathrm{E}-06$ & 114.56 & 46.29 & 68.27 & 24 & $3.91 \mathrm{E}-06$ & $2.08 \mathrm{E}-06$ & $1.52 \mathrm{E}-06$ & 157.51 & 36.84 & 120.67 \\
\hline 4 & $9.84 \mathrm{E}-06$ & $3.01 \mathrm{E}-06$ & 4.82E-06 & 104.15 & 37.48 & 66.67 & 25 & $1.88 \mathrm{E}-06$ & 8.81E-07 & $5.91 \mathrm{E}-07$ & 218.14 & 49.08 & 169.06 \\
\hline 5 & $1.28 \mathrm{E}-05$ & $8.59 \mathrm{E}-06$ & 5.64E-06 & 126.67 & 52.27 & 74.40 & 26 & $2.84 \mathrm{E}-07$ & $1.83 \mathrm{E}-07$ & $1.28 \mathrm{E}-07$ & 121.09 & 42.21 & 78.87 \\
\hline 6 & $1.19 \mathrm{E}-05$ & $8.26 \mathrm{E}-06$ & $5.52 \mathrm{E}-06$ & 116.32 & 49.74 & 66.58 & 27 & $1.33 \mathrm{E}-06$ & 8.37E-07 & $5.52 \mathrm{E}-07$ & 140.45 & 51.81 & 88.64 \\
\hline 7 & 7.99E-06 & $5.51 \mathrm{E}-06$ & $3.71 \mathrm{E}-06$ & 115.47 & 48.70 & 66.77 & 28 & $9.96 \mathrm{E}-07$ & 7.04E-07 & 4.76E-07 & 109.17 & 47.90 & 61.27 \\
\hline 8 & $7.62 \mathrm{E}-06$ & 4.63E-06 & $3.31 \mathrm{E}-06$ & 130.22 & 40.03 & 90.19 & 29 & $3.40 \mathrm{E}-06$ & $1.96 \mathrm{E}-06$ & $1.20 \mathrm{E}-06$ & 183.50 & 64.00 & 119.50 \\
\hline 9 & 8.58E-06 & 4.56E-06 & $3.29 \mathrm{E}-06$ & 160.77 & 38.48 & 122.30 & 30 & $1.78 \mathrm{E}-06$ & $1.10 \mathrm{E}-07$ & $6.59 \mathrm{E}-07$ & 170.15 & 83.32 & 86.82 \\
\hline 10 & $3.02 \mathrm{E}-06$ & $2.34 \mathrm{E}-06$ & $1.41 \mathrm{E}-06$ & 114.20 & 65.84 & 48.35 & 31 & $2.52 \mathrm{E}-07$ & $1.17 \mathrm{E}-06$ & $3.26 \mathrm{E}-06$ & 92.27 & 64.01 & 28.26 \\
\hline 11 & $1.66 \mathrm{E}-06$ & $9.41 \mathrm{E}-07$ & $6.33 \mathrm{E}-07$ & 161.36 & 48.65 & 112.71 & 32 & $1.19 \mathrm{E}-06$ & $3.61 \mathrm{E}-07$ & $5.77 \mathrm{E}-07$ & 106.10 & 37.48 & 68.62 \\
\hline 12 & $1.27 \mathrm{E}-06$ & $8.40 \mathrm{E}-07$ & $5.63 \mathrm{E}-07$ & 124.72 & 49.18 & 75.54 & 33 & $7.80 \mathrm{E}-07$ & 4.95E-07 & $3.67 \mathrm{E}-07$ & 112.30 & 34.76 & 77.54 \\
\hline 13 & $1.34 \mathrm{E}-05$ & $9.16 \mathrm{E}-06$ & $6.17 \mathrm{E}-06$ & 117.70 & 48.38 & 69.32 & 34 & $7.21 \mathrm{E}-07$ & $5.08 \mathrm{E}-07$ & $3.46 \mathrm{E}-07$ & 108.68 & 47.11 & 61.58 \\
\hline 14 & $1.97 \mathrm{E}-08$ & $9.57 \mathrm{E}-08$ & $2.87 \mathrm{E}-07$ & 93.11 & 66.59 & 26.52 & 35 & $6.85 \mathrm{E}-07$ & 4.39E-07 & $3.09 \mathrm{E}-07$ & 121.62 & 41.96 & 79.65 \\
\hline 15 & $1.84 \mathrm{E}-06$ & $1.23 \mathrm{E}-06$ & 8.71E-07 & 111.45 & 41.62 & 69.83 & 36 & $3.59 \mathrm{E}-07$ & $2.27 \mathrm{E}-07$ & $1.75 \mathrm{E}-07$ & 104.78 & 29.69 & 75.09 \\
\hline 16 & $1.56 \mathrm{E}-06$ & $8.17 \mathrm{E}-07$ & $5.68 \mathrm{E}-07$ & 174.74 & 43.89 & 130.86 & 37 & 8.69E-08 & $5.45 \mathrm{E}-08$ & $4.08 \mathrm{E}-08$ & 113.29 & 33.75 & 79.54 \\
\hline 17 & $6.00 \mathrm{E}-07$ & $4.42 \mathrm{E}-07$ & 2.97E-07 & 101.97 & 48.70 & 53.26 & 38 & $4.58 \mathrm{E}-07$ & $3.34 \mathrm{E}-07$ & $2.42 \mathrm{E}-07$ & 89.11 & 38.00 & 51.11 \\
\hline 18 & $1.87 \mathrm{E}-06$ & $1.16 \mathrm{E}-06$ & 7.94E-07 & 136.15 & 45.90 & 90.26 & 39 & $1.68 \mathrm{E}-06$ & $1.06 \mathrm{E}-06$ & $8.17 \mathrm{E}-07$ & 105.53 & 29.80 & 75.73 \\
\hline 19 & $3.00 \mathrm{E}-06$ & $1.75 \mathrm{E}-06$ & $1.25 \mathrm{E}-06$ & 139.82 & 39.86 & 99.96 & 40 & $4.80 \mathrm{E}-07$ & $3.03 \mathrm{E}-07$ & $2.21 \mathrm{E}-07$ & 116.80 & 36.95 & 79.85 \\
\hline 20 & $1.97 \mathrm{E}-06$ & $1.23 \mathrm{E}-06$ & 8.49E-07 & 132.30 & 44.76 & 87.54 & 41 & $9.80 \mathrm{E}-09$ & $2.64 \mathrm{E}-07$ & $3.95 \mathrm{E}-07$ & 97.52 & 33.33 & 64.19 \\
\hline 21 & 1.29E-08 & 9.91E-07 & $1.34 \mathrm{E}-06$ & 99.03 & 25.85 & 73.18 & 42 & $8.56 \mathrm{E}-06$ & $5.99 \mathrm{E}-06$ & $4.06 \mathrm{E}-06$ & 111.09 & 47.54 & 63.55 \\
\hline \multicolumn{14}{|c|}{$X=[7897,7799,7750,7750,7701,7653,7628,7579,7530,7437,7339,7265,7192,7264,7019,7093,6969,6993,6374,6472,6569,6641,6739,6836,6932,7005,5864,5864,5670,559,5402,5304,5207,50$} \\
\hline \multicolumn{14}{|c|}{$\begin{array}{l}85,4038,3843,3648,3453,3259,3064,2844,2770] ; \quad Y=[6071,6101,6101,6101,6131,6162,6223,6284,6315,5697,5789,5850,5942,6035,6157,6126,6341,6434,4517,4549,4581,4643,4674,4706, \\
4830,4923,4329,4329,4296,4296,4294,4293,4293,4292,4284,4283,4281,4280,4278,4308,4368,4522] ; Z=1.5\end{array}$} \\
\hline
\end{tabular}



at monitoring point No.38 (30 $\mathrm{min})$, and the maximum value $(218.14 \%)$ occurs at monitoring point No.25 (30 $\mathrm{min})$, with an average error percentage of $126.07 \%$. The minimum value (20.51\%) of $d_{2}$ occurred at monitoring point No.17 (20 $\left.\mathrm{min}\right)$, and the maximum value $(87.64 \%)$ occurred at monitoring point No.32 $(10 \mathrm{~min})$, with an average error percentage of $50.33 \%$. The minimum value of $d_{3}(26.52 \%)$ occurred at monitoring point No.14 (30 min), and the maximum value $(169.06 \%)$ occurred at monitoring point No.25 (30 min), with an average error difference of $75.74 \%$. Compared with the analytical solution, the prediction accuracy of improved 4DVAR algorithm is significantly improved.

Based on the experimental parameter setting and STI calculation, the diffusion process, situation distribution and isosurface of tracer at different times are simulated and visualized.

(1) Simulation of diffusion process at different times

Figure 13 shows the simulated distribution of tracer diffusion concentration at $5 \mathrm{~min}$, $10 \mathrm{~min}, 15 \mathrm{~min}, 20 \mathrm{~min}, 25 \mathrm{~min}$ and $30 \mathrm{~min}$ along the wind direction.

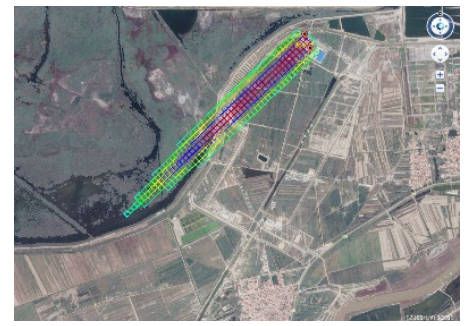

(a) $t=5 \mathrm{~min}$

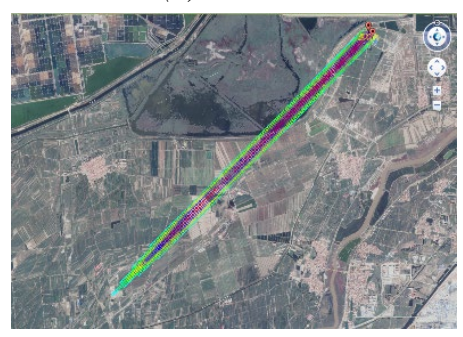

(d) $t=20 \mathrm{~min}$

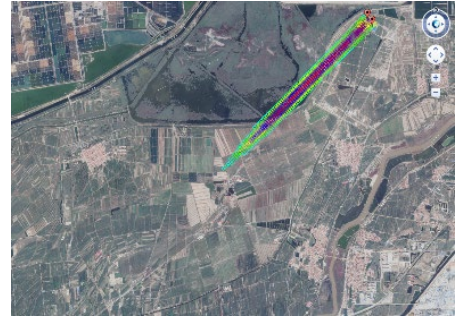

(b) $t=10 \mathrm{~min}$

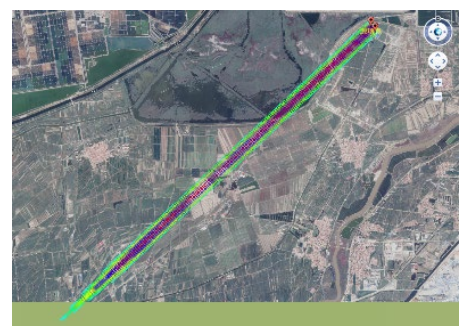

(e) $t=25 \mathrm{~min}$

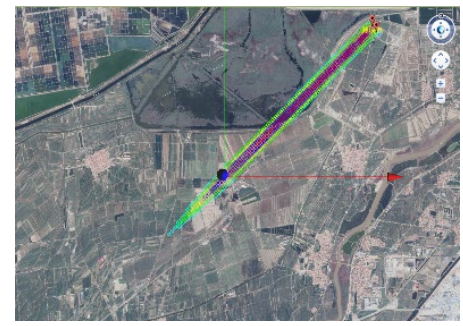

(c) $t=15 \mathrm{~min}$

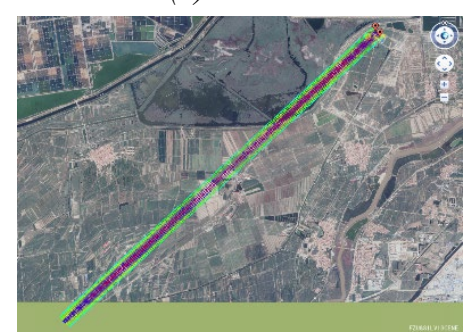

$(f) t=30 \mathrm{~min}$

Fig.13 $\mathrm{SF}_{6}$ diffusion concentration at each time along the wind direction

As can be seen from Figure 13, with the increase of time, $\mathrm{SF}_{6}$ gradually spreads to the downwind area along the wind direction. In case of interference from buildings or high walls, $\mathrm{SF}_{6}$ will be transported with the air flow from both sides or above. As the underlying surface of the whole diffusion space is relatively flat, there is no slowdown or retention.

(2) Situation analysis at different times 
Taking the height $h=1.5 \mathrm{~m}$ as an example, the situation distribution of tracer at $5 \mathrm{~min}$, $10 \mathrm{~min}, 15 \mathrm{~min}, 20 \mathrm{~min}, 25 \mathrm{~min}$ and $30 \mathrm{~min}$ along the wind direction is simulated and analyzed, as shown in Figure 14.

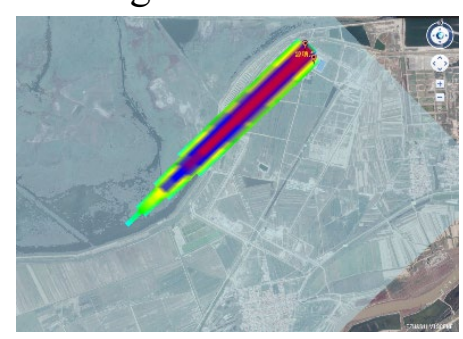

(a) $t=5 \min$

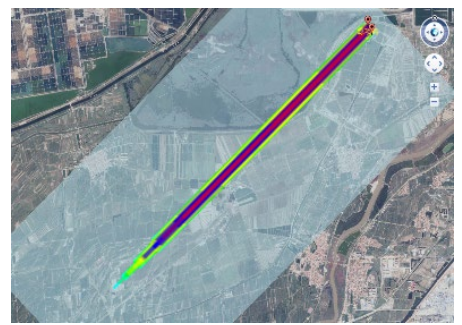

(d) $t=20 \mathrm{~min}$

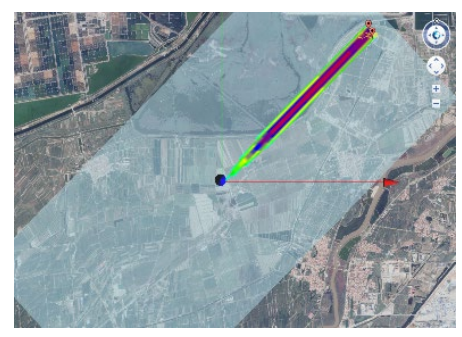

(b) $t=10 \mathrm{~min}$

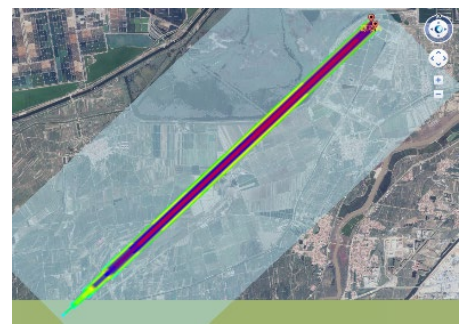

(e) $t=25 \mathrm{~min}$

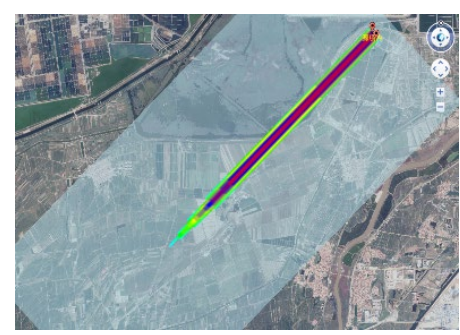

(c) $t=15 \mathrm{~min}$

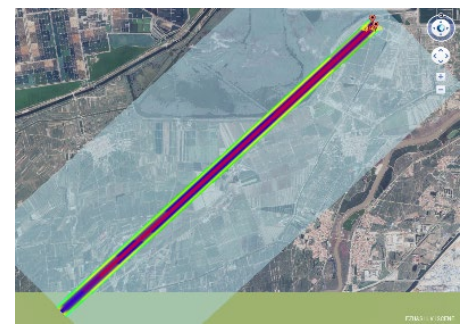

(f) $t=30 \mathrm{~min}$

Fig. 14 Distribution of $\mathrm{SF}_{6}$ diffusion situation at each time

As can be seen from Figure 14, along the wind direction, with the increase of diffusion area, the $\mathrm{SF}_{6}$ concentration gradually decreases and spreads outward. At the same time, under the continuous release of two point sources, the area close to the source is greatly affected by the source term and the situation is relatively complex. With the increase of distance, the impact of the source term is gradually weakened and the situation is gradually regularized.

(3) Isosurface diffusion simulation analysis

Still take the height of $1.5 \mathrm{~m}$ as an example, extract the equivalent data at this height according to the extraction rules of severe pollution $0.001 \mathrm{mg} / \mathrm{m}^{3}$, moderate pollution 0.00001 $\mathrm{mg} / \mathrm{m}^{3}$ and mild pollution $0.00000001 \mathrm{mg} / \mathrm{m}^{3}$, and draw the equivalent surface, as shown in Figure 15.

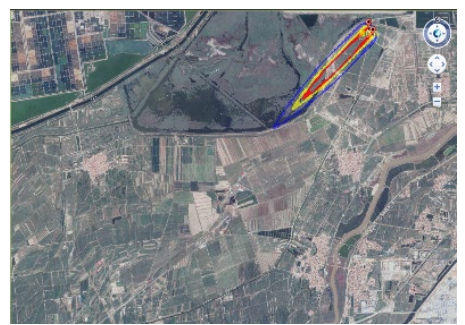

(a) $t=5 \min$

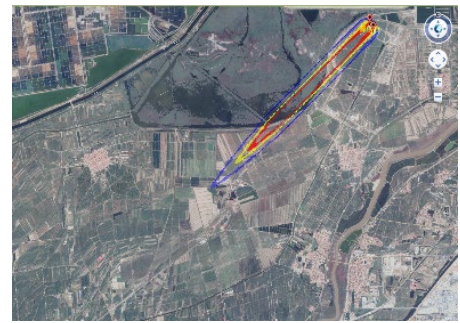

(b) $t=10 \mathrm{~min}$

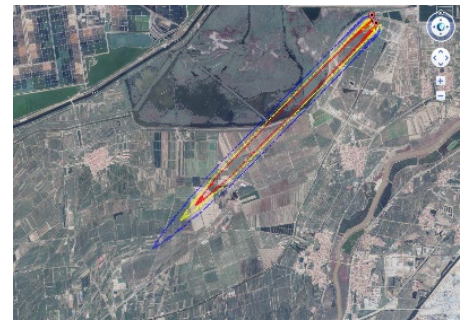

(c) $t=15 \mathrm{~min}$ 


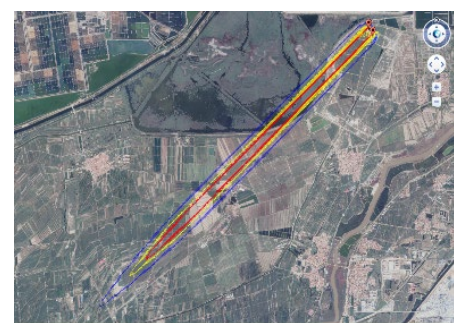

(d) $t=20 \mathrm{~min}$

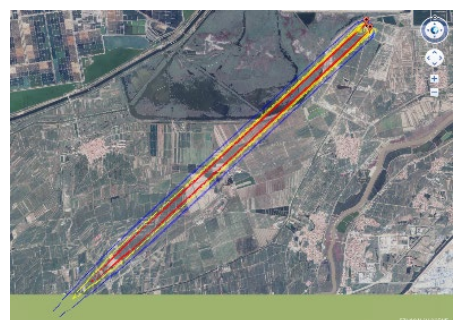

(e) $t=25 \mathrm{~min}$

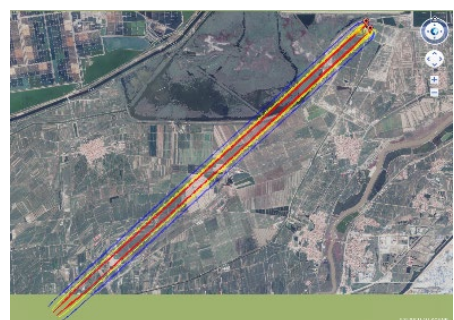

(f) $t=30 \mathrm{~min}$

Fig. $15 \mathrm{SF}_{6}$ concentration isosurface at each time

It can be seen from Figure 15 that the $\mathrm{SF}_{6}$ concentration isosurface at each time presents a regular curve distribution, indicating that the main influencing factor is convection, and the underlying surface and turbulence are not obvious, which is due to the selected height and the flatness of the underlying surface.

\subsection{Discussion of experimental results}

5.3.1 Advantages and disadvantages analysis of inversion algorithm

In order to further verify the advantages and disadvantages of the inversion algorithm, KF, EnKF, 4DVAR and improved 4DVAR are used to calculate the experiments in this section. The number of experiments is set to 20, and the inversion results are compared and analyzed, as shown in Table 8.

Tab.8 Comparative analysis of STI algorithms

\begin{tabular}{cccc}
\hline \multirow{2}{*}{ STI algorithm } & Average value of $\epsilon_{\text {intension }}$ & Average value of $\epsilon_{\text {location }}$ & Experimental success rate \\
\hline KF & $107.56 \%$ & $230.62 \%$ & $50 \%$ \\
EnKF & $85.22 \%$ & $198.38 \%$ & $60 \%$ \\
4DVAR & $65.32 \%$ & $195.50 \%$ & $90 \%$ \\
Improved 4DVAR & $35.37 \%$ & $158.04 \%$ & $100 \%$ \\
\hline
\end{tabular}

It can be seen from Table 8 that the improved 4DVAR algorithm is higher than other algorithms in both inversion accuracy and inversion success rate. The relative error of sources intension estimation can be reduced from $107.56 \%$ to $65.32 \%$, and the relative error of sources location estimation can be reduced from $230.62 \%$ to $195.50 \%$. By improving the adaptability of 4DVAR, the relative error of sources intension estimation can be reduced from $65.32 \%$ to $35.37 \%$, the relative error of sources location estimation can be reduced from $195.50 \%$ to $158.04 \%$, the success rate can be increased from $90 \%$ to $100 \%$, whose STI ability is significantly improved.

5.3.2 Advantages and disadvantages analysis of optimization algorithm

Although IFPA has good effect in system efficiency optimization, its convergence and stability for 4DVAR model calculation have not been effectively verified. Therefore, on the basis of section 5.3.2, Genetic Algorithm (GA), Particle Swarm Optimization (PSO) and FPA 
are used to calculate the experiment for 20 times, and compared with Quasi Newton Algorithm (QNA) and IFPA, as shown in Table 9. The convergence curves of the objective functional under different algorithms are shown in Figure 16.

Tab.9 Advantages and disadvantages comparison of five optimization algorithms

\begin{tabular}{|c|c|c|c|c|}
\hline Algorithms & Parameters setting & $\begin{array}{c}\text { Average value of } \\
\epsilon_{\text {intension }} \\
\end{array}$ & $\begin{array}{c}\text { Average value of } \\
\epsilon_{\text {location }}\end{array}$ & $\begin{array}{l}\text { Average value of } \\
J_{4 D}(\boldsymbol{C}) \text { minimum }\end{array}$ \\
\hline QNA & $\varepsilon=0.5$ & $65.32 \%$ & $195.50 \%$ & $20.3 \%$ \\
\hline GA & $\xi=0.95, C_{r}=0.5$ & $52.50 \%$ & $178.60 \%$ & $15.7 \%$ \\
\hline PSO & $\omega=0.95, C_{l}=0.5, C_{2}=0.5, V_{m}=1$ & $45.28 \%$ & $170.10 \%$ & $12.8 \%$ \\
\hline FPA & Section 5.2 .1 & $38.06 \%$ & $162.50 \%$ & $12.3 \%$ \\
\hline IFPA & Section 5.2 .1 & $35.37 \%$ & $158.04 \%$ & $9.3 \%$ \\
\hline
\end{tabular}

$\varepsilon$----Allowable error, $\xi$---- Variation factor, $C_{r}$---- Crossover probability,

$\omega$---- Inertia factor, $C_{1} 、 C_{2}$---- Learning factor, $V_{m}$---- Maximum speed

It can be seen from Table 9 that in the inversion of sources intensity, the inversion errors of IFPA, FPA, PSO and GA are effectively reduced compared with QNA, indicating that the intelligent optimization algorithm is an important way to improve the solution ability of 4DVAR. In the sources location inversion, the position errors of the five algorithms are almost the same, and the average deviation is more than $150 \%$, where the location of the hazard source can be further determined through the active traceability of the mobile platform. Finally, compared with the other four algorithms, IFPA has smaller error and higher accuracy, whether it is sources intension, sources location or target functional minimum, which shows obvious advantages in global optimization and optimization accuracy.

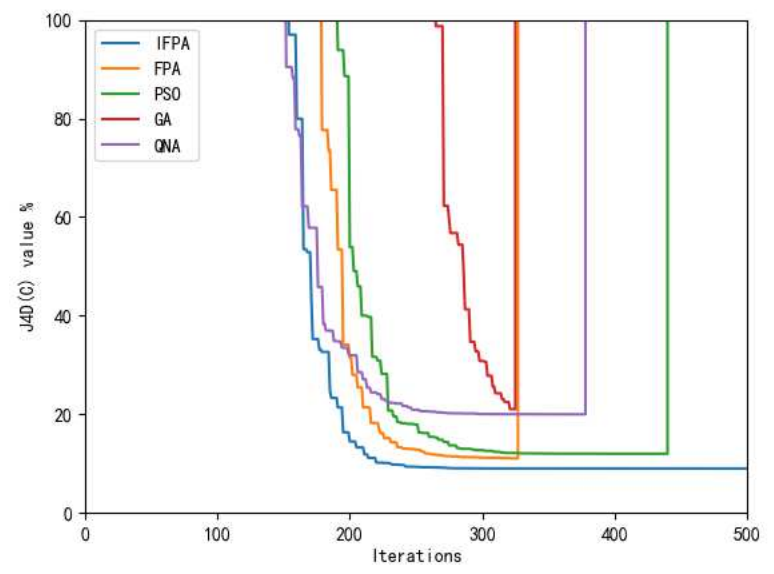

Fig.16 Convergence curve of target functional of five algorithms

As can be seen from Figure 16, IFPA, FPA and PSO are relatively high in convergence accuracy. In terms of convergence speed, IFPA is faster than other algorithms, and can find the optimal solution of the target functional in about 200 generations. In terms of algorithm stability, 
IFPA always searches smoothly after finding the optimal solution until the end of the iteration, and the other four algorithms jump, where the execution error of algorithm cross mutation strategy may be caused by too large calculation dimension, indicating that IFPA also has good stability in the iterative solution of gradient model.

\section{Conclusion}

In this paper, the inverse problem of source intensity and source location estimation in multi-point sources continuous release is discussed. A Taylor series upwind difference scheme based on the solution of the forward problem is proposed. An improved 4DVAR algorithm is used for effective numerical simulation inversion and tracer test verification, which show that the improved 4DVAR algorithm can realize the STI under the conditions of unknown intensity, unknown location, unknown intensity and location, and the accuracy, stability and convergence of the algorithm can meet the traceability requirements. Next, the inversion of instantaneous release and mixed release of multi-point sources will be studied.

Conflict of interest: The authors declare no conflicts of interest.

Data Availability Statement: The data used to support the findings of this study are available from the corresponding author upon request.

\section{REFERENCE}

Andrew J. Annunzio, George S. Young, Sue Ellen Haupt., 2012. Utilizing state estimation to determine the source location for a contaminant. Atmospheric Environment. 46, 580-589.

Castelli S.T., Tinarelli G., Reisin T., 2017. Comparison of atmospheric modelling systems simulating the flow, turbulence and dispersion at the microscale within obstacles. Environ. Fluid Mech. 17 (5), 879-901.

Chabot V., Berre L., Desroziers G., 2017. Diagnosis and normalization of gridpoint background-error variances induced by a block-diagonal wavelet covariance matrix. Quarterly Journal of the Royal Meteorological Society. Vol. 143, No. 704, 1268-1279.

Cullen M. J. P., 2003. Four-dimensional variational data assimilation: A new formulation of the background-error covariance matrix based on a potential-vorticity representation. Q. J. R. Meteorol. Soc. 129, 2777-2796.

Fairbairn D., Pring S. R., Lorenc A. C., 2014. A comparison of 4DVar with ensemble data assimilation methods. Quarterly Journal of the Royal Meteorological Society. Vol. 140, No. 678, 281-294.

François De I'Isle, Robert G. Owens, 2021. Superconsistent collocation methods with applications to convection-dominated convection-diffusion equations. Journal of Computational and Applied Mathematics. 391, 113367. https://doi.org/10.1016/j.cam.2020.113367.

Genc D., Yesilyurt Canan, Tuncel Gurdal, 2010. Air pollution forecasting in Ankara, Turkey using air pollution index and its relation to assimilative capacity of the atmosphere. Environmental Monitoring and Assessment. Vol.166, No.1-4, 11-27.

Hamba Fujihiro, Abe Satoshi, Kitazawa Daisuke, Kato Shinsuke, 2012. Filtering for the inverse problem of convection-diffusion equation with a point source. Journal of the Physical Society of 
Japan. 81, 114401. http://dx.doi.org/10.1143/JPSJ.81.114401.

Hassan K., Saima M., Izaz A., Poom K., Dumitru B., Muhammad A., 2020. Approximate analytical fractional view of convection-diffusion equations. Open Physics. 18, 897-905.

He W. P., Feng G. L., Dong W. J., Li J. P., 2004. Comparison with solution of convection-diffusion by several difference schemes. ACTA PHYSICA SINICA. Vol. 53, No. 10, 3258-3264. (in Chinese)

Huang S. X., Liu F., Sheng L., et al., 2018. Air pollution traceability based on adjoint method. Science Bulletin. 63, 1594-1605. (in Chinese)

Jianbing Jin, Hai Xiang Lin, Heemink, A., Segers, A., 2018. Spatially varying parameter estimation for dust emissions using reduced-tangent-linearization 4DVar. Atmospheric Environment. Vol. 187, 358-373.

Karl Barnes, 2017. Mathematical Methods of Physics. Magnum Publishing.

Kazakov A. L., Spevak L. F., 2021. Exact and approximate solutions of a problem with a singularity for a convection-diffusion equation. Journal of Applied Mechanics and Technical Physics. Vol. 62, No. 1, 18-26.

Kim Sung-Min, Kim Hyun Mee, 2019. Forecast Sensitivity Observation Impact in the 4DVAR and Hybrid-4DVAR Data Assimilation Systems. Journal of Atmospheric \& Oceanic Technology. Vol. 36, No. 8, 1563-1575.

Kuo C. L., Liu C. S., Chang J. R., 2016. The modified polynomial expansion method for identifying the time dependent heat source in two-dimensional heat conduction problems. International Journal of Heat and Mass Transfer. 92, 658-664.

Liu C. S., Chen Y. W., Chang J. R., 2019. Solving a nonlinear convection-diffusion equation with source and moving boundary both unknown by a family of homogenization functions. International Journal of Heat and Mass Transfer. Vol. 138, 25-31.

Liu H. L., 2021. Analysis of direct discontinuous Galerkin methods for multi-dimensional convectiondiffusion equations. Numerische Mathematik. 147, 839-867. https://doi.org/10.1007/s00211-02101183-X.

Liu Y., Li H., Sun S. D., Fang S., 2017. Enhanced air dispersion modelling at a typical Chinese nuclear power plant site: Coupling RIMPUFF with two advanced diagnostic wind models. Journal of Environmental Radioactivity. Vol. 175-176, No. 9, 94-104.

Liu Y., Liu X. J., Li H., et al., 2019. Numerical study on source term inversion of truncated total least squares variation. Nuclear power engineering. Vol. 40, No. 1, 120-125. (in Chinese)

Liu YA, Huang HLA, Gao W, Lim Agnes H. N., Liu CS, Shi RH., 2015. Tuning of background error statistics through sensitivity experiments and its impact on typhoon forecast. Journal of Applied Remote Sensing. Vol.9, No.1, 096051.

Liu Y. A., Li Z. L., Huang M. L., 2019. Towards a data-derived observation error covariance matrix for satellite measurements. Remote Sens. 11, 1770-1794.

Ma Jianwen et al., 2013. Research and experiment of Data Assimilation Algorithm. Beijing: Science Press. (in Chinese)

Naus S., Montzka S. A., Patra P. K., Krol M. C., 2021. A three-dimensional-model inversion of methyl chloroform to constrain the atmospheric oxidative capacity. Atmos. Chem. Phys., 21, 4809-4824.

Pan Dartzi, 2017. A high-order finite volume method for solving one-dimensional convection and diffusion equations. Numerical Heat Transfer, Part B. Vol. 71, No. 6, 533-548. https://doi.org/10.1080/10407790.2017.1326769.

Pan Y. P., Wang Y. S., 2015. Atmospheric wet and dry deposition of trace elements at 10sites in Northern 
China. Atmospheric Chemistry and Physics. Vol. 15, No. 2, 951-972.

Parrish D. F., Derber J. C., 1992. The National Meteorological Center's Spectral Statistical Interpolation analysis system. Mon Wea Rev. 120, 1747-1763.

Quinn C., O'kane T.J., Kitsios V., 2020. Application of a local attractor dimension to reduced space strongly coupled data assimilation for chaotic multiscale systems (Article). Nonlinear Processes in Geophysics. Vol. 27, No. 1, 51-74.

Reza Pourgholi, Akram Saeedi, Abbas Hosseini, 2019. Determination of nonlinear source term in an inverse convection-reaction-diffusion problem using radial basis functions method. Iranian Journal of Science and Technology, Transactions A: Science. Vol. 43, 2239-2252. https://doi.org/10.1007/s40995-017-0379-6.

Ruan Z. S., Zhang S., 2020. Simultaneous inversion of time-dependent source term and fractional order for a time-fractional diffusion equation. Journal of Computational and Applied Mathematics. Vol. $368,112566$.

Rutherford I., 1972. Data assimilation by statistical interpolation of forecast error fields. Atmospheric Science. 29, 9-15.

Sun C. L., Li G. S., Jia X. Z., 2017. Simultaneous inversion for the diffusion and source coefficients in the multi-term TFDE. Inverse Problems in Science and Engineering. Vol.25, No.11, 1618-1638.

Varella H., Berre L., Desroziers G., 2011. Diagnostic and impact studies of a wavelet formulation of background-error correlations in a global model. Q. J. R. Meteorol. Soc. 137, 1369-1379.

Veronika Valler, Jorg Franke, Stefan Brönnimann, 2019. Impact of different estimations of the background-error covariance matrix on climate reconstructions based on data assimilation. Climate of the Past. Vol. 15, No. 4, 1427-1441.

Viktor Popov, Tu Thanh Bui, 2010. A meshless solution to two-dimensional convection-diffusion problems. Engineering Analysis with Boundary Elements. 34, 680-689.

Wang L., Yang X. G., Wang H. L., Chai Z. H., Wei Z. C., 2021. A modified regularized lattice Boltzmann model for convection-diffusion equation with a source term. Applied Mathematics Letters. 112, 106766. https://doi.org/10.1016/j.aml.2020.106766.

Wei T., Xu M. T., 2016. An integral equation approach to the unsteady convection-diffusion equations. Applied Mathematics and Computation. Vol.274, No.C, 55-64.

Yang X. S., 2012. Flower pollination algorithm for global optimization. International Conference on Unconventional Computing and Natural Computation. 240-249.

Yasumasa Miyazawa, Max Yaremchuk;Sergey M. Varlamov, Toru Miyama, Kunihiro Aoki, 2020. Applying the adjoint-free 4dVar assimilation to modeling the Kuroshio south of Japan. Ocean Dynamics. Vol. 70, No. 8, 1129-1149.

Zhu X. Z., Han C. S., Liu R. Q., Yan G. H., Gu J., 2021. One universal method of complex system reliability, maintainability, supportability, testability quotas design and trade-off based on improved flower pollination algorithm. Quality Reliability Engineering International, Vol. 37, No. 4, 1524-1543.

Zhang J. C., Wang Y. P.,2014. A method for inversion of periodic open boundary conditions in twodimensional tidal models(Article). Computer Methods in Applied Mechanics and Engineering. Vol. 275, 20-38. 